\title{
Airtightness measurement of an outdoor chamber using the Pulse and blower door methods under various wind and leakage scenarios
}

\author{
$\underline{\text { Xiaofeng Zheng }}{ }^{* 1}$, Joe Mazzon ${ }^{2}$, Ian Wallis ${ }^{2}$, Christopher J Wood ${ }^{1}$ \\ 1 Buildings, Energy and Environment Research \\ Group, \\ Faculty of Engineering, University of Nottingham \\ University Park, Nottingham NG7 2RD, UK \\ 2 BSRIA Limited \\ Old Bracknell Lane West \\ Bracknell, Berkshire, RG12 7AH, UK
}

*Corresponding author: xiaofeng.zheng@nottingham.ac.uk

\begin{abstract}
As a continued investigation following the previous testing of a house-sized chamber in a sheltered environment, this paper introduces an experimental study of airtightness measurement of an outdoor chamber using both the novel Pulse technique and the steady pressurisation method. The chamber has dimensions of approximately half that of a standard 20ft long shipping container. The chamber's envelope was modified with multiple openings to provide a leakage level similar to that of an average UK house. Two sets of experimental tests were carried out independently at different times to investigate: a) How both methods compare on measuring the airtightness of an outdoor chamber at various leakage levels; and b) How the steady wind at various wind speed may affect the Pulse measurement of the chamber airtightness. Results show that the air permeability at $4 \mathrm{~Pa}$ measured by both methods has a percentage difference less than $16 \%$ in most testing scenarios, which is a slightly larger discrepancy than that found in the sheltered environment study. In steady wind tests, artificial wind at various speed levels was introduced in the Pulse tests by utilising a multi-gear portable trailer fan. Initial findings have shown that the impact of steady wind on the Pulse test is mostly insignificant when it is under $3.5 \mathrm{~m} / \mathrm{s}$. However, high wind speeds ( $4 \mathrm{~m} / \mathrm{s}-9.5 \mathrm{~m} / \mathrm{s})$ decrease the value of air permeability at $4 \mathrm{~Pa}$ by $16 \%-24 \%$ in comparison to that measured under the fan-off condition in the steady wind tests.
\end{abstract}




\section{KEYWORDS}

Infiltration, Building airtightness measurement, Blower door, The Pulse technique, Steady wind impact

\section{NOMENCLATURE}

Symbol

$\begin{array}{cl}A & \text { Area of opening }\left(\mathrm{m}^{2}\right) \\ a, b & \text { Coefficients of quadratic equation for the leakage-pressure } \\ C & \text { relationship } \\ \frac{d q}{d t} & \text { Flow coefficient }\left(\mathrm{m}^{3} / \mathrm{s} / \mathrm{Pa}^{\mathrm{n}}\right) \\ l_{e} & \text { Building pressure change rate }(\mathrm{Pa} / \mathrm{s}) \\ \mathrm{n} & \text { Effective length of opening }(\mathrm{m}) \\ \Delta P & \text { Pressure exponent in eq. }(3) \\ P_{i} & \text { Building pressure }(\mathrm{Pa}) \\ Q & \text { Internal pressure of the chamber }(\mathrm{Pa}) \\ Q_{4} & \text { Building air leakage rate }\left(\mathrm{m}^{3} / \mathrm{s}\right) \\ Q_{50} & \text { Air permeability at } 4 \mathrm{~Pa}\left(\mathrm{~m}^{3} / \mathrm{h} / \mathrm{m}^{2}\right) \\ Q_{p}\{t\} & \text { Air permeability at } 50 \mathrm{~Pa}\left(\mathrm{~m}^{3} / \mathrm{h} / \mathrm{m}^{2}\right) \\ q\{t\} & \text { Transient volumetric flow rate of air pulse }\left(\mathrm{m}^{3} / \mathrm{s}\right) \\ t & \text { Transient building air leakage rate }\left(\mathrm{m}^{3} / \mathrm{s}\right)\end{array}$

Greek letter
$\rho_{i}$
Indoor air density $\left(\mathrm{kg} / \mathrm{m}^{3}\right)$
$\gamma$
$\delta q_{V}$
$\delta V$
Specific heat ratio of air, 1.4
Measurement error of the chamber leakage rate in percentage
Measurement error of the chamber volume in percentage

\section{INTRODUCTION}

In order to tackle the issues caused by global warming, policy makers have set a number of carbon reduction targets across the major sectors. The recent 'emission reduction plan' set by the UK government is a good example of efforts made at a national level to limit global temperature rise to around $2{ }^{\circ} \mathrm{C}$. It emphasizes the importance of focusing on cutting carbon 
emissions in multiple sectors and reflects the UK's efforts to support the more ambitious international action: 'Paris Agreement', which was reached in December 2015 [1]. Cutting carbon emission in the building sector has become increasingly necessary due to its greater potential for further reduction.

It has been widely recognised that airtightness has a significant impact to building energy efficiency $[2,3]$ because the air infiltration, fundamentally determined by airtightness, contributes significantly to a building's energy consumption associated with heating and cooling. The impact has been studied in various studies over last few decades, some $[4,5,6,7]$ estimated infiltration is responsible for up to $13-30 \%$ of building heating losses and $4-14 \%$ of cooling losses, while others $[8,9,10,11,12]$ found the impact is more significant (up to 50\%). In addition, airtightness is an important indicator of building quality because it affects not only the building thermal performance, but also the indoor air quality and building durability in the long term. Buildings with high-energy performance have been sought globally in the pursuit of minimizing carbon emission in the building sector $[13,14,15]$.

As a widely accepted steady pressurisation method for measuring building airtightness, the blower door method takes measurements in a range of high pressures, which are typically in 10-60 Pa but vary with weather conditions and operative's preference. Certain test criteria needs to be followed to obtain valid measurements. For instance, ISO 9972 [16] requires that, the achieved pressure range has to be greater than $25 \mathrm{~Pa}$ and the pressure interval between adjacent measurements should be less than $10 \mathrm{~Pa}$. In addition, recommendations are given on the number of measurements and the corresponding averaging time length under different weather conditions. The test is implemented by creating a steady pressure difference across the building envelope by blowing air into or drawing air out of the building with the assistance of 
a fan blower and measuring the corresponding airflow rate through it simultaneously. The air leakage result is typically quoted at $50 \mathrm{~Pa}$ or $4 \mathrm{~Pa}$, sometimes at $10 \mathrm{~Pa}, 25 \mathrm{~Pa}, 75 \mathrm{~Pa}$ and 100 $\mathrm{Pa}$ [17] which are used as reference pressures for equivalent leakage area and leakage measurements of windows [18] or ducts [19]. Table 1 lists the regulatory minimum requirement for the building airtightness of new buildings in a number of countries where different reference pressures are used. More details about the requirements in other countries are summarised in [20].

Table 1 Regulatory requirement for airtightness of new buildings in different countries

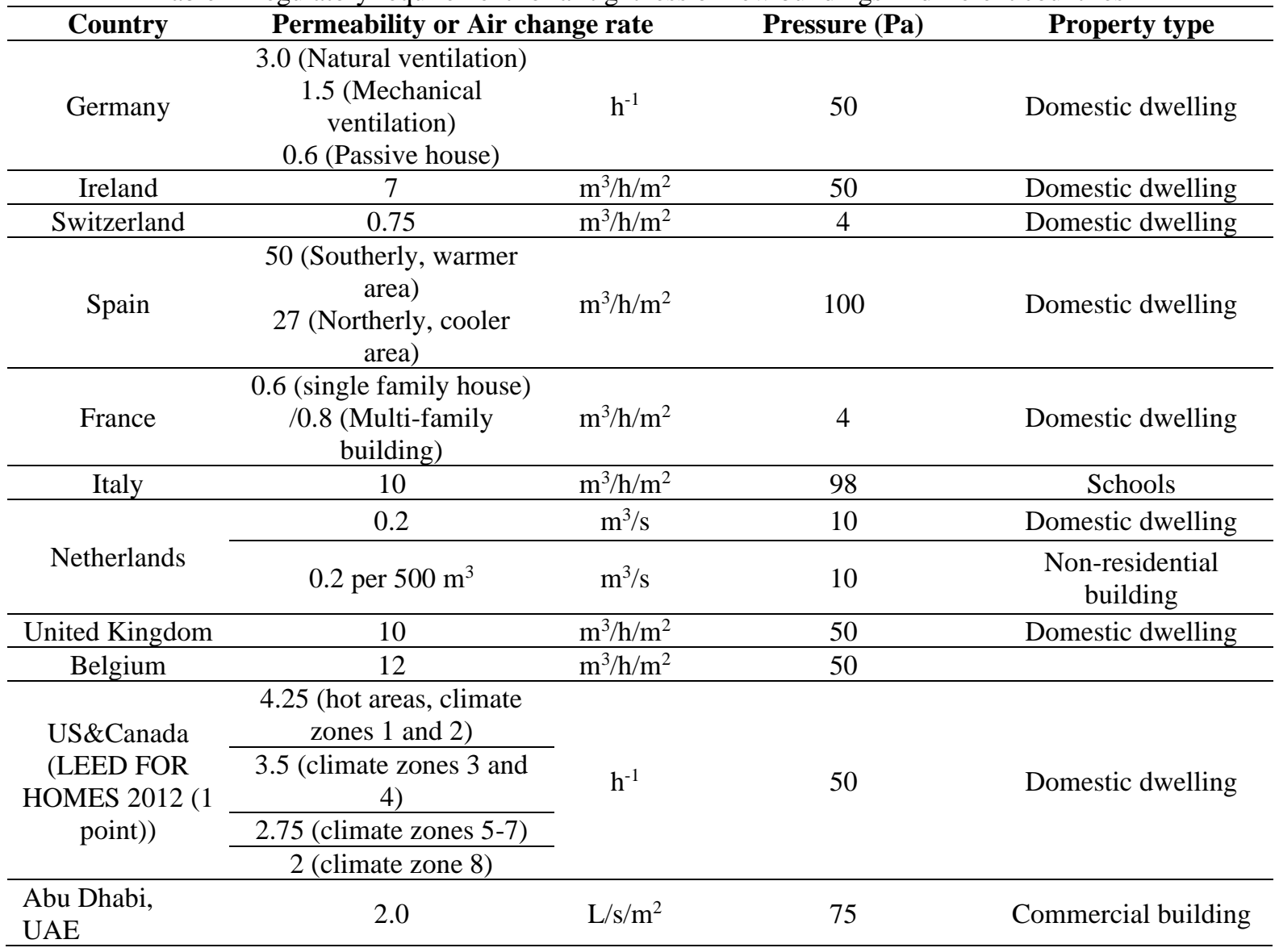

The Pulse technique, developed to take measurements at low pressures (typically in 1-10 Pa), rapidly releases a pulse of air from a compressed air tank into the test building over a short period of time (seconds) and creates an instantaneous pressure rise followed by steady pressure drop. The underlying principle is the achievement of a quasi-steady flow, which can be shown 
to exist via the temporal inertial model and further detail is given by Cooper et al $[21,22]$. The pressure variations in both building and air tank are measured by pressure transducers alongside temperatures and used for establishing the leakage-pressure relationship of that building. The air leakage result is then quoted at a low pressure, i.e. $4 \mathrm{~Pa}$, which is seen as a typical weatherinduced pressure level $[17,23,24]$. The research on the Pulse technique has been ongoing for over 16 years and the Pulse prototype development has been through a number of stages during that time. However, due to the dynamic nature of the Pulse measurement, questions have been frequently raised by peer scientists and practitioners regarding its principle, technical feasibility, practicality and adoptability. For instance, the pressure uniformity in the test building during the Pulse test has been questioned due to the nature of short and dynamic operation and the resulted accuracy of such test is therefore not reliable. However, studies $[25,26]$ showed that uniform pressure distribution was observed in the Pulse test and an insignificant impact on the accuracy was created when the Pulse test was performed at various locations within spaces of both single zone and multiple zones. A study based on the similar Pulse concept $[27,28]$ has been undertaken to measure the effective leakage area of a test room but insufficient accuracy was achieved in comparison to the steady pressurisation method due to the inconsideration of either air compressibility or inertia effect of unsteady flow. Nevertheless, efforts have been ongoing to collate scientific evidence from both lab-based and in-situ research studies in an attempt to provide useful answers to those questions [29], with the historical and ongoing research focused on the theoretical study, numerical analysis and a considerable number of experimental investigations. As part of the investigations, the study reported herein aims to provide an experimental insight on how both testing methods correlate in the leakage measurement of an outdoor chamber in a range of leakage scenarios and also how the Pulse measurement is affected by artificially introduced steady wind. 
The wind impact is one of the major contributors to the measurement uncertainty of building airtightness or infiltration rate $[30,31]$. There has been a lack of experimental investigations on that aspect. Analyses of wind impact using the theoretical approach have been carried out by Carrie and Leprince [3232,], who found an uncertainty of 6\%-12\% can be caused by steady wind in the range of $6-10 \mathrm{~m} / \mathrm{s}$ combined with other sources of error in a steady state test at 50 $\mathrm{Pa}$. This uncertainty increases up to $33 \%$ when the quoted pressure is decreased to another commonly used reference level, i.e. $4 \mathrm{~Pa}$ [17]. However, Leprince and Carrie highlighted in different studies [33, 34,] that the wind impact is less noticeable for wind speed below $6 \mathrm{~m} / \mathrm{s}$. They also found that direct measurements at $50 \mathrm{~Pa}$ minimises the uncertainty (below 10\%) of measurement when the wind speed is up to $9 \mathrm{~m} / \mathrm{s}$. Although the pressure of interest is different, the impact of steady wind on the measurement uncertainty reported by Leprince and Carrie seems to be less significant. This different finding perhaps can be explained by the fact that steady wind used in the theoretical study is more stable than that achieved in real case scenarios, where the wind may fluctuate in a range due to various environmental and terrain factors and therefore exhibit a dynamic behaviour. This dynamic nature of wind, also termed as 'wind fluctuation frequency' or 'wind gustiness', was investigated by Kraniotis [35, 36, 37] in a number of numerical and experimental studies where its impact on the infiltration rate was studied. The results showed that higher wind fluctuation frequency potentially led to greater air change rate and the estimation uncertainty also became greater. This finding is not directly applicable to its impact on the measurement of building airtightness, but it suggests the measurement of building pressure can be significantly affected by the dynamic and unpredictable nature of wind. In addition, the leakage distribution and wind direction might also change how the wind affects the pressure profile of test building. 
Previous investigations related to the use of the Pulse technique are mainly focused on its proof of concept, validations of the Pulse prototypes at different developmental stages and its comparison with the blower door method in various testing scenarios [29]. The impact of environmental conditions on the measurement of building airtightness using the Pulse technique has been studied in a detached UK house over a year during which various environmental conditions were captured [38] and it was found that the measurement uncertainty lay within $\pm 8 \%$. However, prior to this work there had been no research performed to solely investigate the wind impact on the measurement of envelope airtightness using the Pulse technique.

This paper, expanded from the previous conference version [39], consists of two separate investigations; a comparison study, in which both testing methods were utilised to assess the envelope airtightness of an outdoor chamber which was exposed to outdoor natural conditions. Therefore, tests reported herein form a continued investigation of the previous one, which compared both testing methods on the airtightness measurements of a house-sized chamber in a sheltered environment [26]. This comparison study in an unsheltered condition, aims to provide complimentary insights as to how both testing methods compare under natural conditions and how an artificially introduced steady wind by means of a trailer fan may affect the measurement of airtightness of the external chamber using the Pulse technique. Due to being carried out within the same test space in a short time window, such experimental investigations allowed us to gain a better understanding of the questions by maintaining the consistency in the test space and minimising the impact of other environmental conditions (temperature, humidity, solar radiation, etc.). The two investigations are named herein as the $\mathrm{NC}$ (natural condition) test and the SW (steady wind) test, respectively. 


\section{BACKGROUND}

\subsection{Blower door method}

In practice, the blower door test is implemented by using a fan blower, which is mounted in an existing fenestration, as shown in Figure 1 (Pressurisation mode).
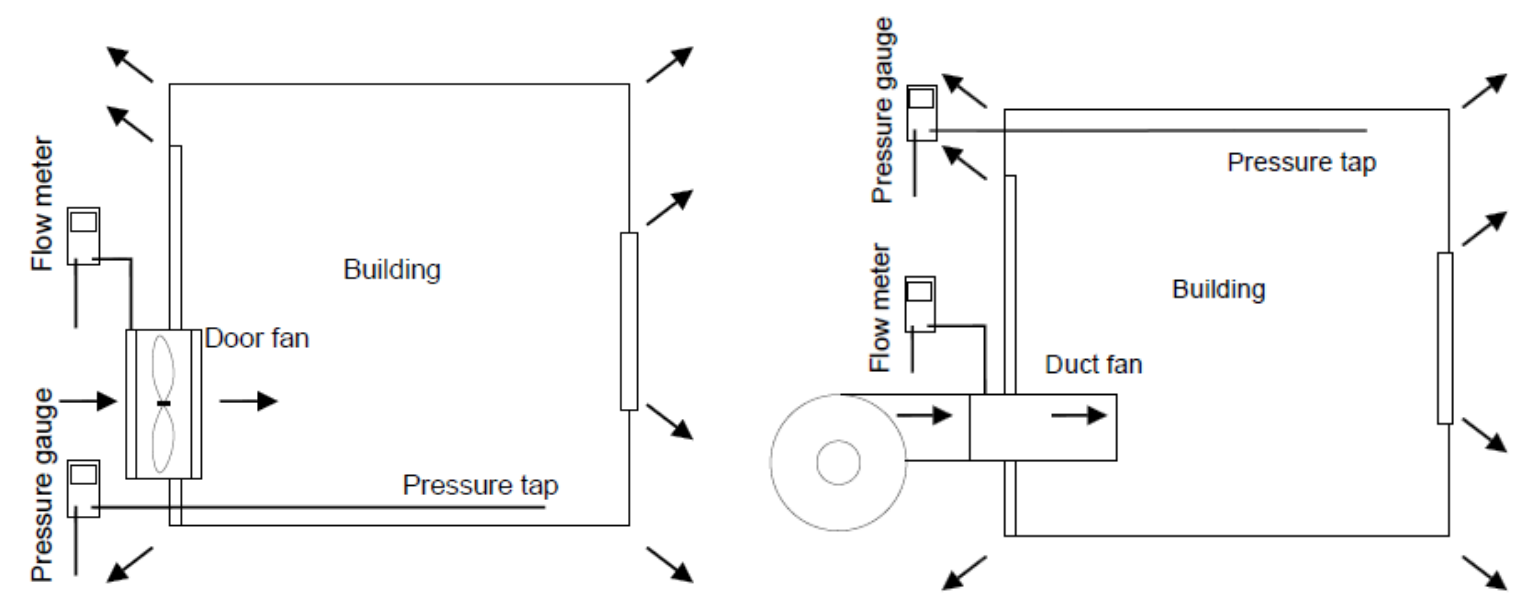

Figure 1 Steady pressurisation method (door fan and duct fan: in pressurisation)

It creates a steady pressure difference across the envelope by blowing air into or drawing air out of the test building and the corresponding airflow rate through the fan and achieved building pressure are recorded by a pressure-flow gauge and used to establish the leakage-pressure relationship. In some countries, such as UK, the flow rate through the fan blower is not directly read but calculated using the recorded fan pressure and the pressure-flow calibration factors produced in the annual calibration process for each fan ring. A leakage-pressure relationship of the test building can then be established to represent the leakage characteristic of the building and a typical example is shown in Figure 2. 


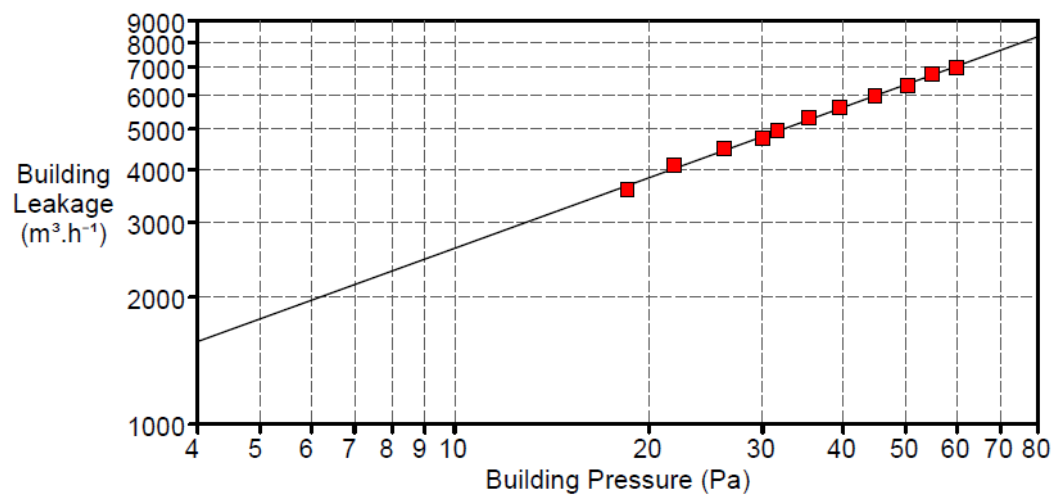

Figure 2 A typical steady state airtightness test (log-log plot)

This technique was firstly used in Sweden around 1977 [17, 40], which paved a foundation to its wider development and acceptance. It was also regarded as a useful tool for weatherization and retrofitting work. Since then it has attracted wide attention and generated high demand in building industry. This technology has gone through significant developments from early bulky and clunky version, which was made of materials like plywood and Formica to the latest lighter and more compact version made of adjustable metal frame and a lightweight fabric door panel. With the test duration reduced significantly, the operations have also become more user friendly.

To date, the blower door has been the most commonly used technique for measuring building airtightness and performing diagnostics in the field. A great deal of studies have been conducted in the last few decades to investigate a wide range of questions in relation to the utilisation of the technique, such as measurement uncertainty [30, 32, 41], its relationship with the infiltration, its impact on ventilation and indoor air quality $[42,43,44,45]$ as well as its practical applications in retrofitting [46, 47, 48]. In addition, it has been adopted as a standard testing method by various standards such as ASTM, CAN/CGSB, ISO etc., and used for demonstrating compliance with building regulations in a number of countries. 
Therefore, as a reliable and accurate means of measuring building airtightness, the blower door method was utilised alongside the Pulse technique to not only provide a benchmark measurement for the purpose of assessing the accuracy of the Pulse technique, but also allow further understanding on how both methods perform and compare under various testing conditions to be obtained.

\subsection{The Pulse technique}

The Pulse technique measures the building airtightness at low pressures by releasing a known volume of air into the test building over 1.5 seconds from an air tank to create an instant pressure rise within the building and reach a "quasi-steady" flow, where the pressure variations in the building and tank are monitored and used for establishing a correlation between leakage and pressure. The method also accounts for changes in background pressure caused by environmental conditions, by deducting background pressure changes from the raw pressure data. Figure 3 illustrates measurements of a typical Pulse test. The building pressure readings in a single Pulse test consist of three key stages, pressure variation during quasi-steady period and background pressures before and after the pulse.

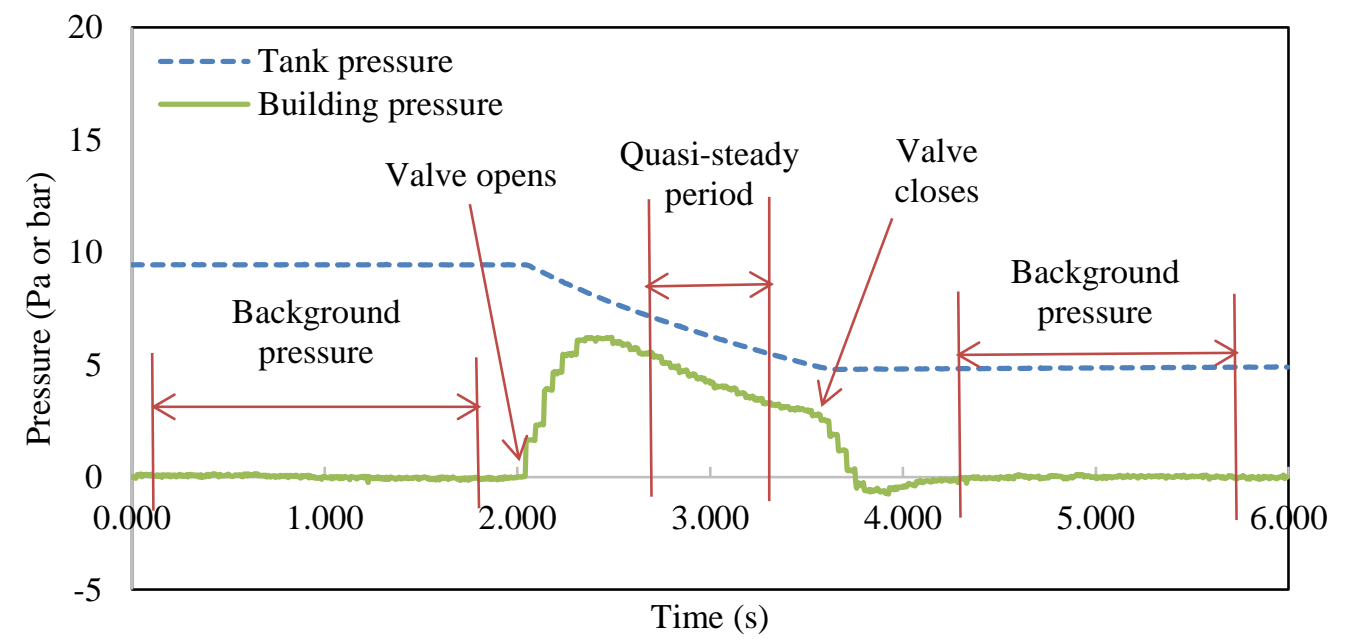


Figure 3 A typical Pulse test by a Pulse unit with 601 tank (tank pressure measured in bar, building pressure in $\mathrm{Pa})[38]$

Different from the blower door method, the Pulse technique takes measurements in a dynamic manner over a range of pressures instead of taking each individual reading at a steady pressure level. Its advantage is that the test can be implemented transiently within 15 seconds and hence provides a consecutive measurement of leakage in a range of building pressures, typically 1$10 \mathrm{~Pa}$. However, such rapid and dynamic approach comes with a challenge, i.e. the occurrence of the inertia effect of air that flows through openings due to the presence of unsteady flow. It then adds uncertainty to the measurement [49], which are described in [21, 38, 50] and therefore not covered in great details here. The percentage of unsteady flow in the quasi-steady period, isolated and quantified using a momentum equation, is used to evaluate that inertia effect. The momentum equation is described by eq.(1).

$$
\Delta p\{t\}=a q\{t\}^{2}+b q\{t\}+\rho_{i} \frac{l_{e}}{A} \frac{d q}{d t}
$$

The first two terms of the right hand side of eq.(1) correspond to the momentum change and surface friction. The third term stands for the inertia effect of the air that flows through the opening, i.e. the unsteady flow term.

Hence, the percentage of unsteady flow can be defined by eq.(2):

$$
\frac{\left|\rho_{i} \frac{l_{e}}{A} \frac{d q}{d t}\right|}{\left|a q\{t\}^{2}+b q\{t\}\right|+\left|\rho_{i} \frac{l_{e}}{A} \frac{d q}{d t}\right|} \times 100 \%
$$

The quasi-steady period [21] lies in the latter part of the pulse as indicated in Figure 3. In order to achieve the "quasi-steady" state, the percentage of unsteady flow has to be small enough 
compared to other terms, usually less than a few percent. The full details of its mathematical representation and numerical validation are beyond the scope of this paper and will be reported elsewhere. More experimental studies based on the Pulse technique, addressing the issues related with repeatability, comparison with steady pressurisation method and testing large buildings during the research and development, are summarised by Zheng et al [29], which includes a comparison study between the Pulse and blower door methods based on tests performed in a range of dwellings [38] and the results showed both tests followed the same trend.

Figure 4 demonstrates an example of quantified unsteady flow of a typical pulse test and less than $4 \%$ (mostly under $2 \%$ ) unsteady flow was experienced during the pulse period (1.5s). However, for the optimal accuracy, the period during which the minimal percentage of unsteady flow is identified and defined as the 'quasi-steady' period. Within the quasi-steady period in this case, the percentage of the unsteady flow is less than $1 \%$.

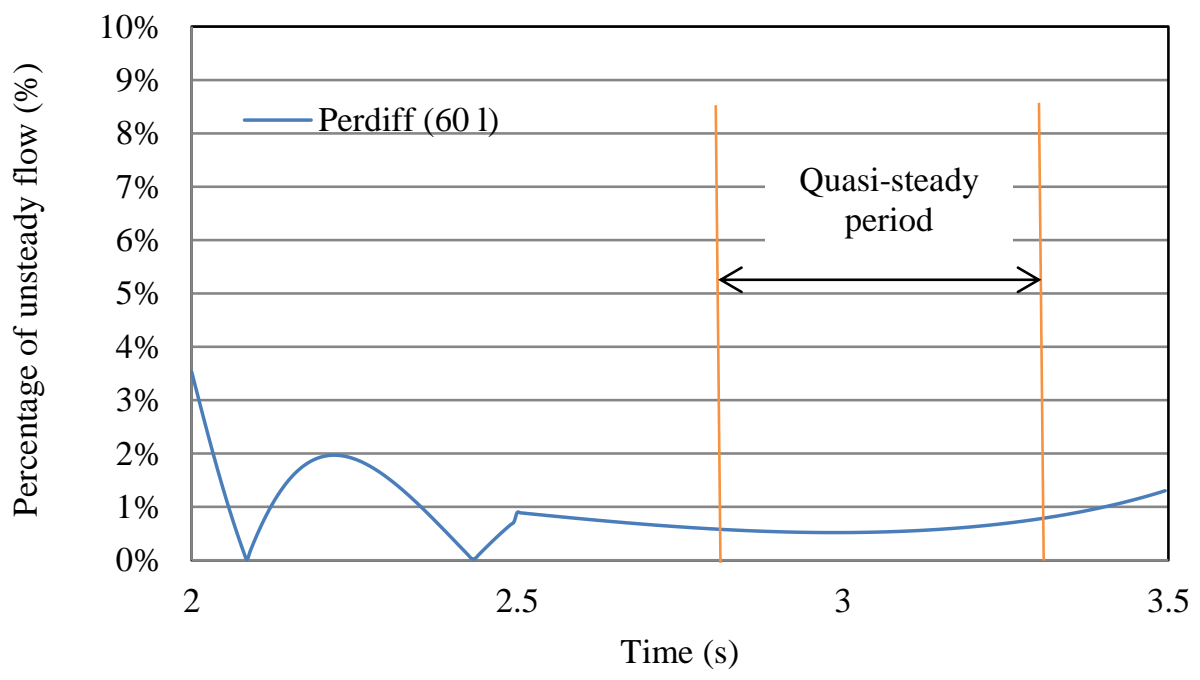

Figure 4 Percentage of unsteady flow of the pulse test in Figure 3 [38] 
When both testing methods are used to measure the airtightness of the same building and provided there is no change in the building envelope during testing, they should provide leakage-pressure curves that follow the same trend, albeit obtained at different pressure levels. Figure 5 shows the log-log graph consisting of leakage-pressure curves obtained in the same building by both testing methods where a clear trend is observed. They can be mathematically represented in the same format using a power law relationship, which is described by eq.(3).

$$
Q=C \times \Delta P^{n}
$$

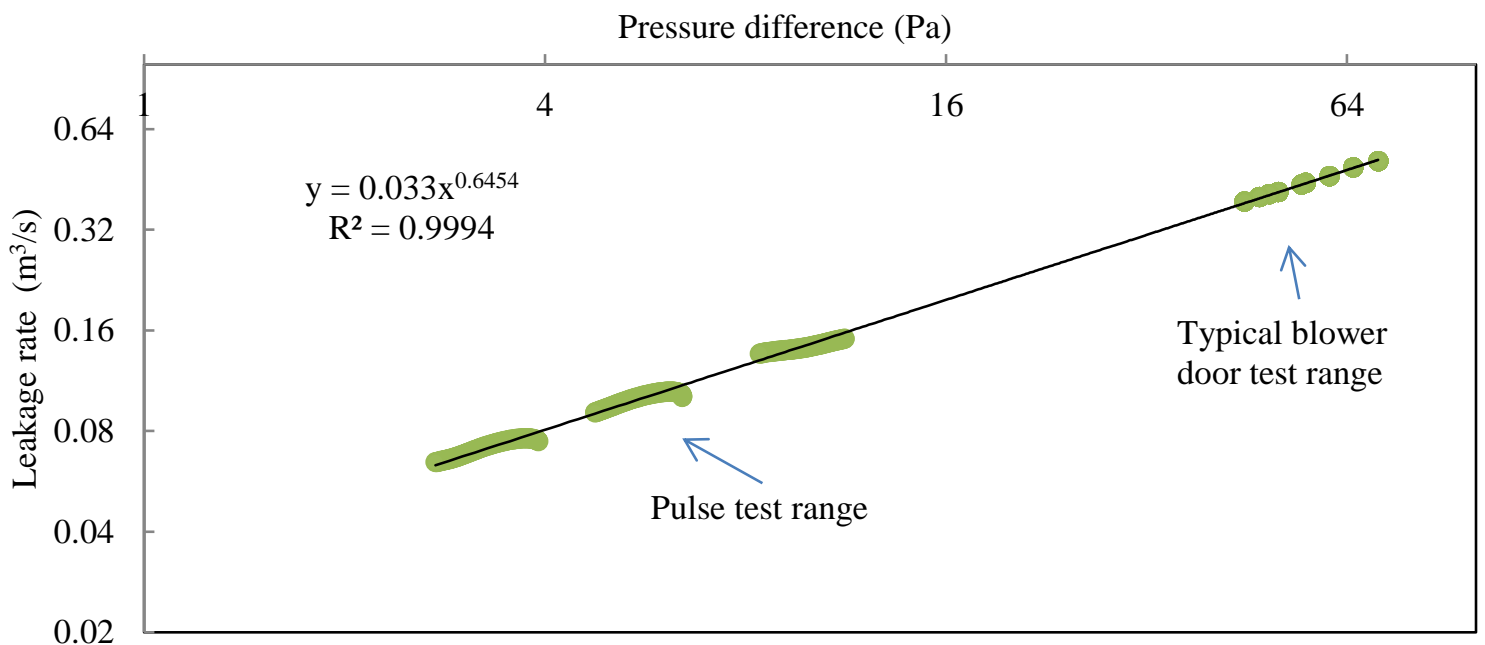

Figure 5 A log-log graph of leakage-pressure relationship measured by pulse and blower door in one building [38]

\section{Experimental design}

\section{1. Equipment}

The main blower door unit used in this study for comparison is a Minneapolis low range blower door model--Duct Blaster B (DBB). As shown in Figure 6, it comprises an adjustable doorframe, a flexible canvas panel, a variable-speed fan, and a DG700 pressure-flow gauge. The DBB was also utilised in the previous comparison study [26] and was therefore used for 
testing alongside the Pulse technique in this study. For one NC test, a larger Minneapolis model-2 blower door unit was used in a single comparison test. A prototype PULSE-80 unit, which consisted of an 80-litre lightweight composite tank, an oil free double piston compressor and a control box, was used in all the NC tests, as shown in Figure 7.

A different Pulse unit, PULSE-60 was used in the SW test due to equipment availability. It incorporated a 58.5-litre lightweight aluminium tank, an oil free compact air compressor and a control box as shown in Figure 8. The Pulse data (chamber pressure, temperature and tank pressure) is recorded and analysed by the control box and results are displayed on the LCD screen embedded in the control box.

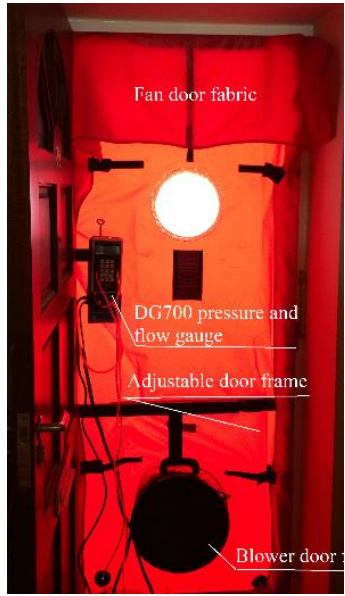

Figure 6 Minneapolis Duct blaster B (DBB)

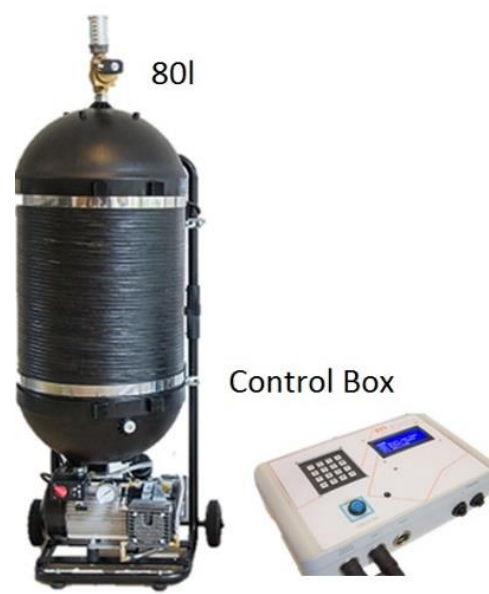

Figure 7 PULSE-80 and associated control box (NC test)

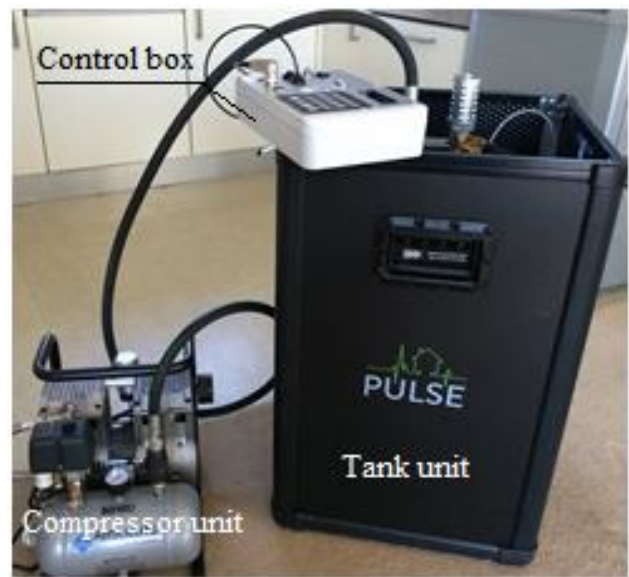

Figure 8 PULSE-60 and associated control box (SW test)

In the SW test, various wind conditions were created for testing using a multi-gear portable trailer fan. The fan was driven by a petrol engine and various fan speeds were achieved by the combination of three different gears and a fan speed controller, as shown in Figure 9. 


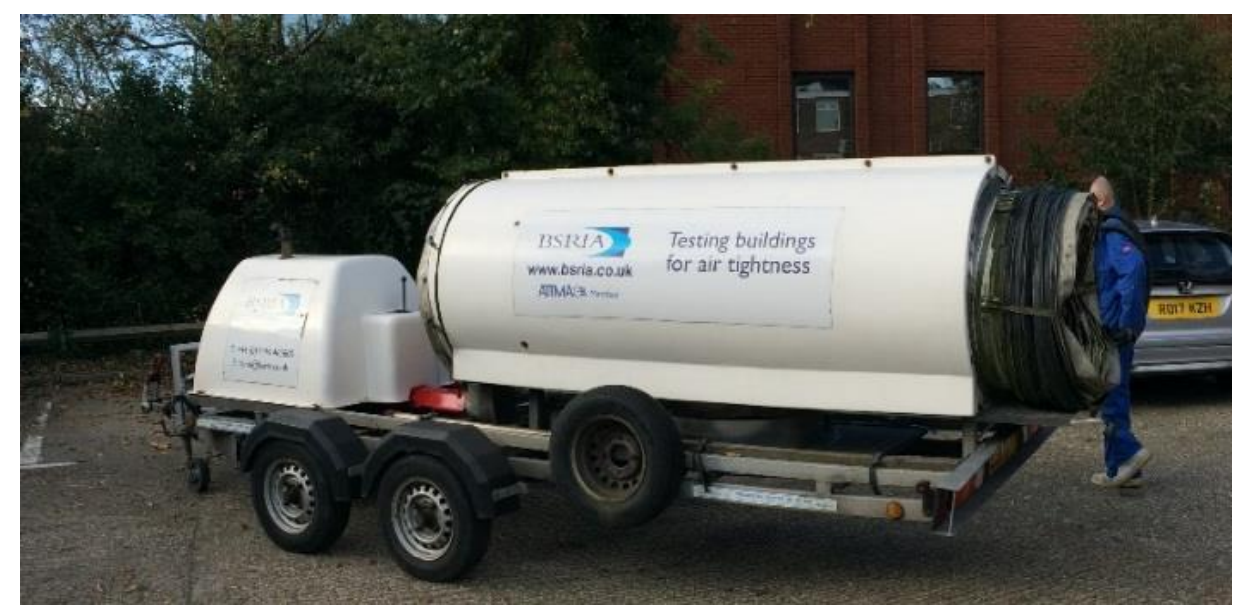

Figure 9 A petrol driven multi-gear portable trailer fan

\section{2. Chamber}

The test chamber used in this experimental work was modified from a standard 20-feet $(6.1 \mathrm{~m})$ long shipping container. It was located in the vicinity of an office building and was divided to two separate spaces by a partition wall. One of them, highlighted by a blue rectangle in Figure 10 , was used for testing. The chamber has dimensions of $2.84 \mathrm{~m} \times 2.23 \mathrm{~m} \times 2.03 \mathrm{~m}$ and background openings (R1-1 in Table 2) were installed in the envelope to provide leakage level that is present in typical domestic buildings. The outdoor chamber was utilised due to availability and access, which enabled various wind speeds to be introduced by using the portable trailer fan. However, it must be noted that this chamber is smaller than that used in the earlier sheltered environment study $[26,54]$.
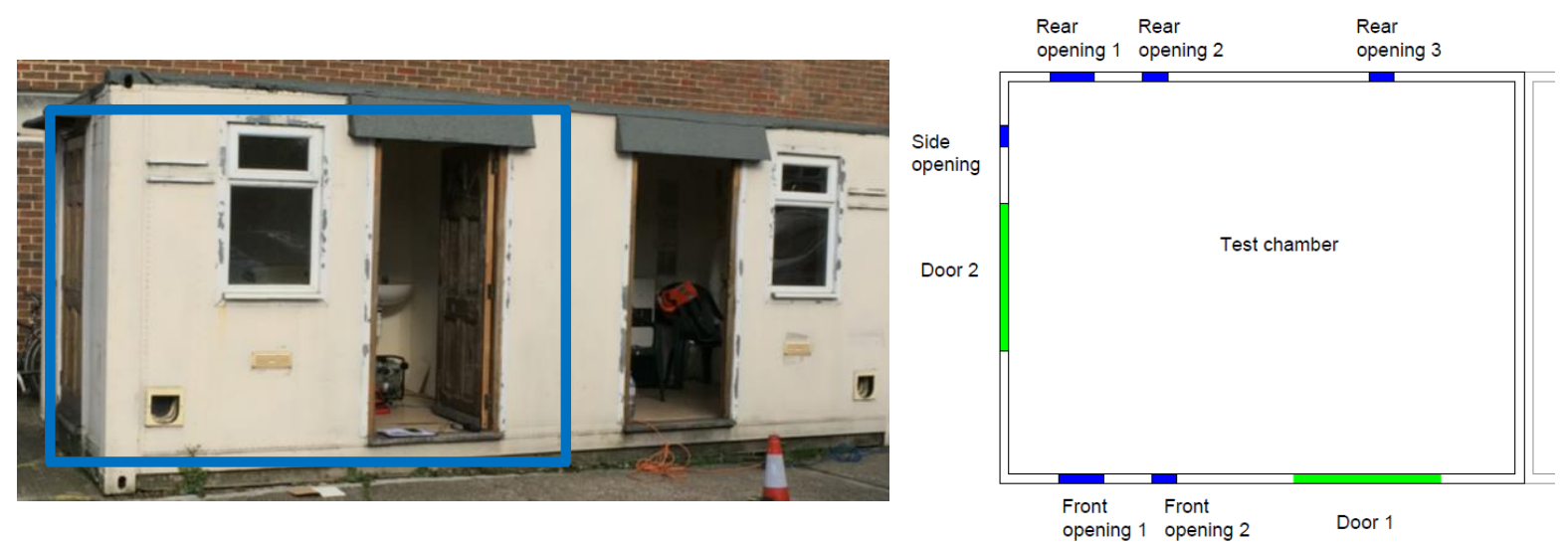
Figure 11 shows the chamber plan of the envelope with various openings. Overall, there are 14 openings. Each opening location represents one or multiple openings at different heights of external walls. Table 2 lists a photograph for each particular opening, at each plan location. These are shown in the table from top to bottom according to their relative physical height. The converted shipping container is fabricated from sheet steel and therefore is inherently more airtight compared to typical wall construction of buildings. It must be noted that the NC and SW tests were carried out with one-year gap in-between, during which the chamber had been used for multiple projects with changes made to the enclosure. Hence, it could not be assured that chamber leakage would be the same for both scenarios and therefore the NC and SW tests are not compared herein. 
Table 2 Openings in the test chamber envelope

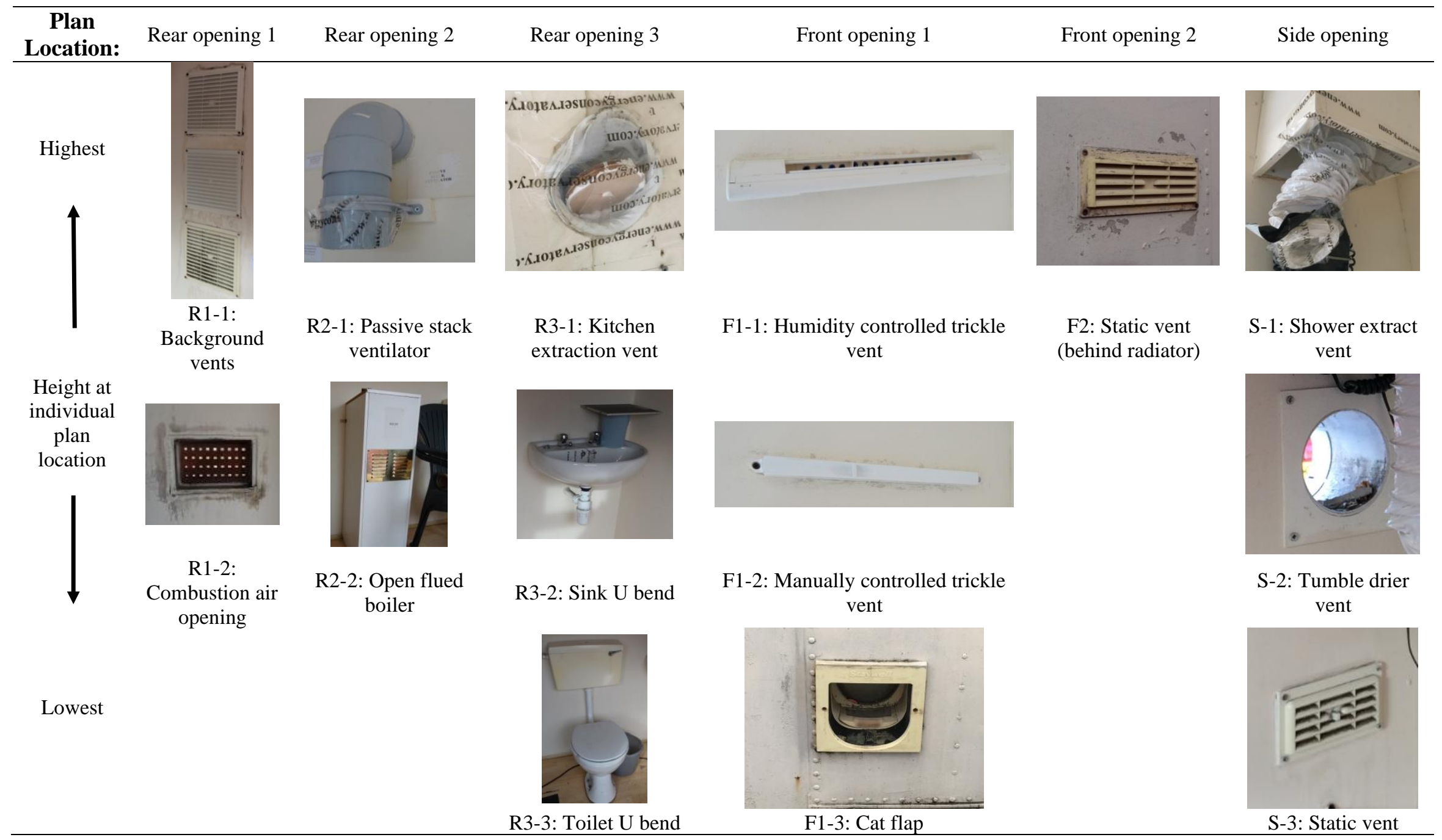




\section{3. Pre-check tests for the Pulse unit setup location}

The internal volume of the test chamber utilised in the study is $13 \mathrm{~m}^{3}$; approximately 20 times smaller than that of a typical UK dwelling. This confined test space may introduce errors, due to enhanced internal reflections of the released air pulse during the test, which consequently makes the accurate measurement of the internal pressure challenging. For the blower door method, care was given to the setup of the pressure tubes to avoid the impact of fan airflow on the reading of chamber pressure during the blower door test. For the Pulse technique, the setup location might have an impact on the test due to its dynamic nature of the measurement and confined space. Therefore, prior to the implementation of experimental investigations, it is essential to carry out pre-check tests to identify if a specific experimental setup for the Pulse unit is required for a scientifically sound experimental study, in particular the setup location.

As a transient testing method, the Pulse technique relies on measurements over a short period of time and can be sensitive to external interferences such as air movement and physical impact to the pressure sensing section for measuring building pressure. Therefore, it is important to eliminate the impact of such factors to obtain valid tests. The pressure sensing section consists of a differential pressure transducer, an internal pressure reference tank and a length of pressure tube, as highlighted in the blue rectangle in Figure 12. The internal pressure reference tank is an airtight vessel, one end of which is connected to the differential pressure transducer via the pressure tube, the other end is connected to an airtight solenoid valve (as indicated by V2 in Figure 12). The valve is normally open to allow the pressure in the reference tank to equalise with surrounding and closes a couple of seconds before test starts to provide a useable pressure reference for measuring pressure change in the test space when it is subject to an air pulse released from the main air tank via the main valve (V1). 
Air movement near the pressure port can be generated by the rapid release of compressed air into the confined space and have a direct impact on the pressure sensing section, which consequently causes fluctuations to the reading of the differential pressure transducer. Hence, the pressure port and tube of the differential pressure transducer (connected to the control box) should be located in a sheltered space to avoid the direct impact of any ejecting air movement from the pulse. Two different positions (position 1 and 2 in Figure 13) for setting up the pulse unit were adopted in the test to see how pulse position affects the results.

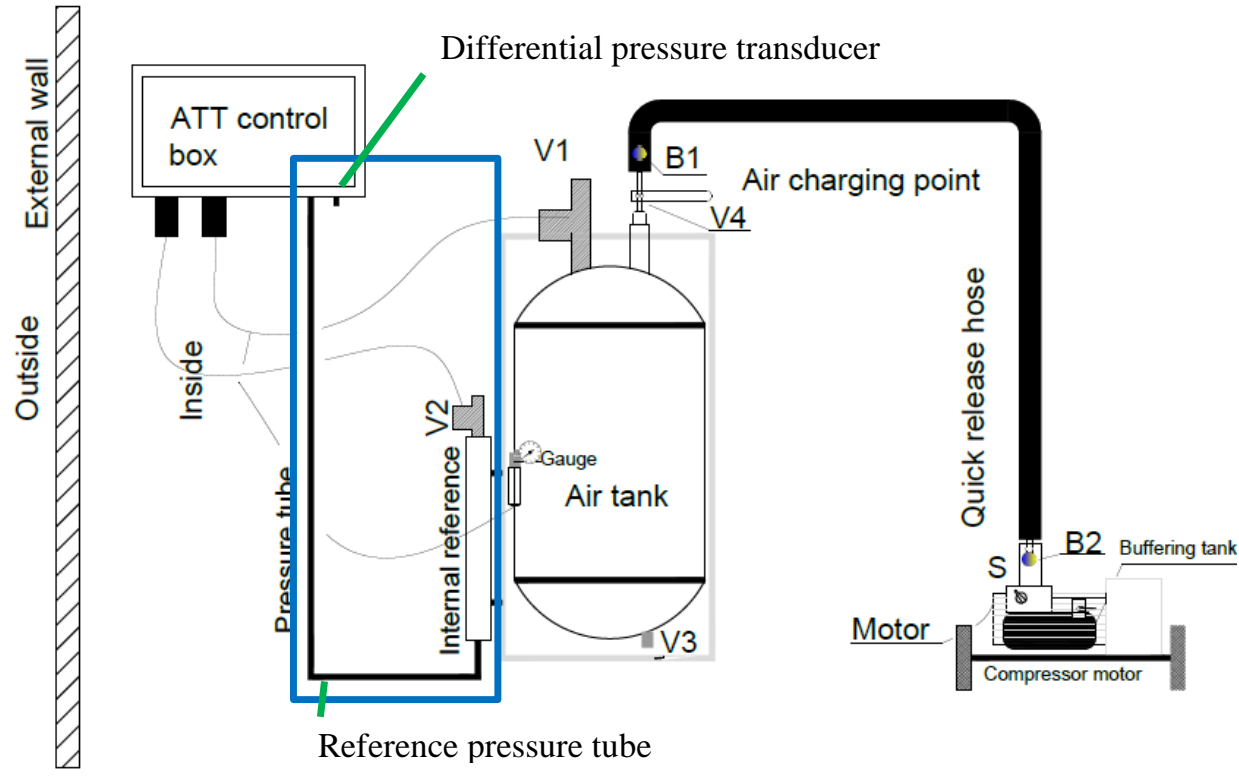

Figure 12 Pressure sensing section for the measurement of building pressure

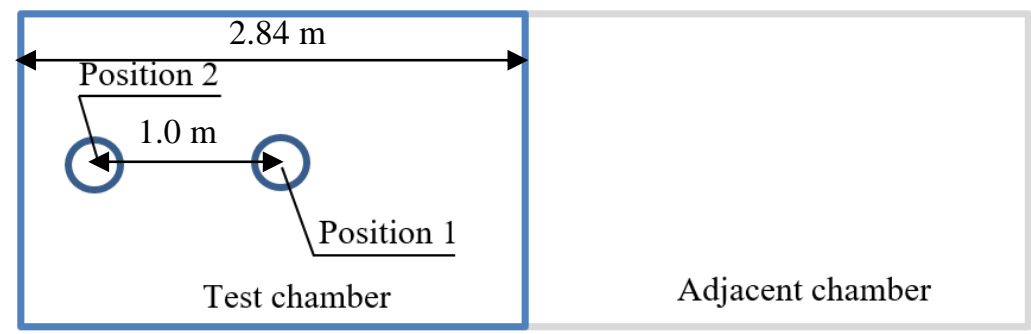

Figure 13 Unit position in the test chamber 
Three repeated tests were carried out at position 1 and were followed by three repeated tests after the pulse unit was moved to position 2. Then another two repeated tests were carried out after it was moved back to position 1 . The results are summarised in Table 3, which shows that the tests at position 1 and 2 gave a measurement uncertainty of $\pm 7.7 \%$ and $\pm 5.5 \%$, respectively. The impact of moving the pulse unit from position 1 to 2 on the measurement of $Q_{4}$ is $1.72 \%$ as a relative percentage difference (RPD), which is within the acceptable variation range of the Pulse measurements [38]. Hence, this finding suggests the setup location of the Pulse unit has minor impact on the measurements. However, the position 1 was selected for the setup of the Pulse unit in the experimental study.

Table $3 Q_{4}\left(\mathrm{~m}^{3} / \mathrm{h} / \mathrm{m}^{2}\right)$ with position changing, jumping and walking

\begin{tabular}{rrrrrr}
\hline $\mathrm{t}$ & 1 & 2 & 3 & Average & RPD \\
\hline Position 1 & 4.41 & 4.79 & 4.14 & $4.45( \pm 7.7 \%)$ & $\mathrm{n} / \mathrm{a}$ \\
\hline Position 2 & 4.13 & 4.44 & 4.54 & $4.37( \pm 5.5 \%))$ & $-1.72 \%$ \\
\hline Position 1 & 4.60 & 4.24 & $\mathrm{n} / \mathrm{a}$ & $4.42( \pm 4.2 \%)$ & $-0.60 \%$ \\
\hline
\end{tabular}

\section{NATURAL CONDITION (NC) TESTS}

\section{1. Testing arrangement}

A range of leakage level was created by sealing up various openings, to achieve 6 testing scenarios as shown in Table 4, thus providing a wide spectrum of leakage characteristics and levels. $Q_{50}$ measured by the blower door is used to indicate the range of leakage levels achieved in the setup and it ranges approximately from 19.1 to $40.7 \mathrm{~m} 3 / \mathrm{h} / \mathrm{m}^{2}$. The corresponding pressure exponents ranged from 0.571 to 0.612 , which are smaller than the average value $(0.66)$ obtained in the study by Orme et al [51] but similar with the range (0.576-0.631) obtained in our previous sheltered environment study [26]. It suggests the flow through leakage pathways experienced in all test scenarios is more turbulent than that experienced in typical buildings. That can be 
attributed to the fact that in this investigation the openings purposely introduced to the chamber were left unsealed to provide different leakage levels, as opposed to sealing such types of openings in the standard method of testing a dwelling. Therefore, theoretically only scenario 1 is comparable with the standard blower door test. However, the pressure exponent in that scenario is 0.571 , which is still much lower value than 0.66 . This difference may be due to the physical differences of the background passive ventilators (R1-1), (which were installed to provide the chamber envelope an air leakage level that is similar to that in typical UK dwellings) compared to that of typical leakage pathways in buildings. Namely, the passive ventilators have ventilator grills, which are effectively large sharp-edged openings and therefore produce more turbulent flow and consequently a smaller pressure exponent. Nevertheless, the achieved leakage levels still allow us to compare the Pulse and blower door methods on measuring the chamber leakage.

Table 4 Openings sealed in various scenarios for the NC tests (Opening ID's as listed in Table 2)

\begin{tabular}{|c|c|c|c|c|c|c|}
\hline Scenario & 1 & 2 & 3 & 4 & 5 & 6 \\
\hline $\mathrm{NC}$ test & All except R1-1 & $\begin{array}{l}\text { All except } \\
\text { R1-1 and } \\
\text { R1-2 }\end{array}$ & $\begin{array}{l}\text { All except } \\
\text { R1-1, R1- } \\
2, \mathrm{~S}-3, \mathrm{~F} 2\end{array}$ & $\begin{array}{c}\text { All except R1- } \\
\text { 1, R1-2, S-3, } \\
\text { F2, F1-1, F1-2, } \\
\text { R3-2, R2-2, S- } \\
\text { 2, R2-1 }\end{array}$ & All unsealed & $\begin{array}{l}\text { All sealed } \\
\text { except R1-1 } \\
\text { and R2-2 }\end{array}$ \\
\hline Descriptor & $\begin{array}{c}\text { Compliance test: } \\
\text { All openings } \\
\text { were sealed } \\
\text { except } \\
\text { background } \\
\text { vents } \\
\end{array}$ & $\begin{array}{l}\text { Air brick } \\
\text { unsealed }\end{array}$ & $\begin{array}{l}\text { Radiator } \\
\text { vent and } \\
\text { static vent } \\
\text { unsealed }\end{array}$ & $\begin{array}{l}\text { Trickle vents, } \\
\text { sink traps, } \\
\text { boiler vent, } \\
\text { dryer vent and } \\
\text { passive stack } \\
\text { vent unsealed } \\
\end{array}$ & $\begin{array}{c}\text { Bathroom } \\
\text { vent, cooker } \\
\text { extract and } \\
\text { shower vent } \\
\text { unsealed }\end{array}$ & $\begin{array}{c}\text { All openings } \\
\text { were sealed } \\
\text { except } \\
\text { background } \\
\text { vents and } \\
\text { boiler vent }\end{array}$ \\
\hline $\begin{array}{c}\mathrm{Q}_{50} \\
\left(\mathrm{~m}^{3} / \mathrm{h} / \mathrm{m}^{2}\right) \\
\end{array}$ & 19.1 & 22.7 & 26.7 & 34.4 & 40.7 & 22.1 \\
\hline $\begin{array}{c}\text { Pressure } \\
\text { exponent, } \\
n\end{array}$ & 0.571 & 0.561 & 0.575 & 0.563 & 0.570 & 0.612 \\
\hline
\end{tabular}

During the blower door test, the DBB was installed in door 2 to perform mostly pressurisation tests but with depressurisation tests also performed in the scenario 1. During the Pulse test, the PULSE-80 unit was placed approximately in the centre of the chamber with both chamber doors closed. The setup of the DBB and PULSE-80 unit is shown in Figure 14 and Figure 15, respectively. The chamber enclosure was prepared according to the ATTMA technical standard 
L1 (the Air Tightness Testing \& Measurement Association) [52] albeit with various sealing arrangements of openings as per Table 4.

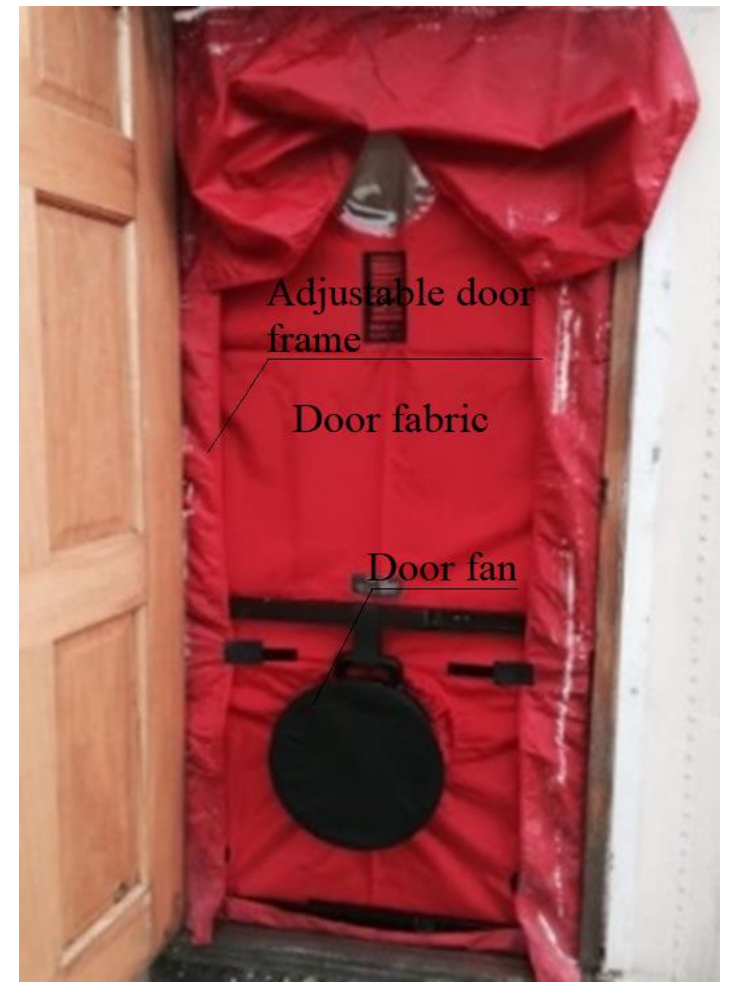

Figure 14 Setup of DBB

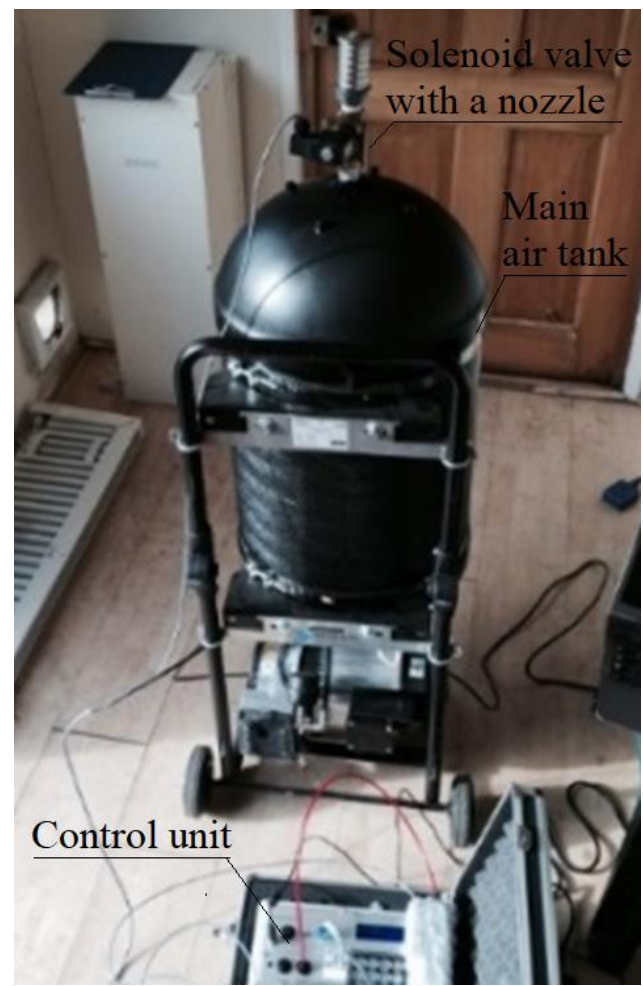

Figure 15 Setup of PULSE-80 unit

In order to minimize the difference in the chamber envelope measured by both testing methods, each leakage scenario was tested by both methods individually before being changed to the next one. The difference introduced to the chamber envelope by the installation of the blower door was not the scope of this study and hence not investigated systematically. However, a comparison check was carried out to investigate the impact of the presence of the installed blower door on the chamber leakage by utilising measurements made by the Pulse technique (Table 6). In the scenario 1 (Table 5), the test was performed three times using each testing method to check for any deviation in repeatability of the measured results. DBB tests were also carried out in both pressurisation and depressurisation modes. Due to time constraints in relation to the test chamber availability all other scenarios were performed once with DBB and PULSE-80 (except for scenario 6, where three pressurisation tests were achieved). Pressurisation mode was used in 
blower door test for a fair comparison with the Pulse test considering the Pulse test pressurises the chamber enclosure.

\section{2. NC Test results}

Considering both testing methods are designed to take airtightness measurement at different pressure levels, direct comparison at either pressure level might lead to significant error [38]. However, the blower door test has the origin to anchor the leakage-pressure curve at the lower end, which reduces its uncertainty in the measurement of $Q_{4}$. Therefore, the $Q_{4}$ is measured for the purpose of comparison. By comparing to the previous comparison study performed under sheltered conditions [26], the results reported herein allow us to gain a good understanding on how outdoor natural conditions may affect the measurements by both testing methods.

Table 5 lists $Q_{4}$ measured by both methods under 6 different scenarios, with the chamber preparation of each scenario described in Table 4 accordingly.

Table $5 Q_{4}\left(\mathrm{~m}^{3} / \mathrm{h} / \mathrm{m}^{2}\right)$ of the chamber measured by DBB and PULSE- 80 under various scenarios

\begin{tabular}{|c|c|c|c|c|c|c|c|}
\hline Scenario & \multicolumn{3}{|c|}{1} & \multicolumn{2}{|c|}{6} & \multicolumn{2}{|c|}{2} \\
\hline Test & $\begin{array}{c}\text { DBB } \\
\text { Pressurise }\end{array}$ & $\begin{array}{c}\text { DBB } \\
\text { Depressurise }\end{array}$ & PULSE-80 & $\begin{array}{c}\text { DBB } \\
\text { Pressurise }\end{array}$ & PULSE-80 & $\begin{array}{l}\text { DBB } \\
\text { Press' }\end{array}$ & $\begin{array}{c}\text { Pulse } \\
-80\end{array}$ \\
\hline 1 & 4.34 & 4.31 & 4.21 & 4.71 & 4.46 & 5.51 & 4.86 \\
\hline 2 & 4.40 & 4.36 & 3.84 & 5.20 & 4.44 & & \\
\hline 3 & 5.10 & 4.53 & 4.33 & 5.55 & 4.53 & & \\
\hline Mean & $4.61( \pm 10.5 \%)$ & $4.40( \pm 3.0 \%)$ & $4.13( \pm 6.9 \%)$ & $5.15( \pm 8.6 \%)$ & $4.48( \pm 1.2 \%)$ & & \\
\hline Scenario & \multicolumn{2}{|c|}{3} & \multicolumn{2}{|c|}{4} & \multicolumn{2}{|l|}{5} & \\
\hline Test & $\begin{array}{c}\text { DBB } \\
\text { Pressurise }\end{array}$ & PULSE-80 & $\begin{array}{l}\mathrm{DBB}(\mathrm{Pa}) \\
\text { Pressurise }\end{array}$ & PULSE-80 & PULSE-80 & $\begin{array}{l}\text { DBB } \\
\text { Press' }\end{array}$ & \\
\hline 1 & 6.24 & 5.78 & 8.31 & 7.43 & 9.66 & 8.31 & \\
\hline
\end{tabular}

The three repeated tests performed with both testing methods in scenario 1 , show that in the pressurisation and depressurisation tests a deviation from the mean of $\pm 10.5 \%$ and $\pm 3.0 \%$ was seen respectively, whilst the Pulse test showed a deviation of $\pm 6.9 \%$. The testing results given by both pressurisation and depressurisation showed a good agreement with each other by $4.6 \%$ 
in deviation. In comparison with the Pulse test result, the pressurisation DBB test and depressurisation DBB test gave a deviation of $11.6 \%$ and $6.5 \%$, respectively, with a mean of $9.1 \%$.

From scenario 1 to scenario 5, the leakage level of the chamber envelope increased due to the number of openings being unsealed. In scenario 6 , the chamber preparation was changed back to scenario 1 but with the boiler vent unsealed (note the order in Table 4). The changing trend of chamber leakage level measured by the DBB in pressurisation mode and PULSE-80 is illustrated in Figure 16, which shows the results given by both methods follow the same trend. However, the result given by DBB is consistently higher than that given by PULSE-80 by $7.9 \%-16.2 \%$; whereas in the previous investigation in a sheltered environment [54] the relative percentage difference ranged from $-9.84 \%$ to $8.22 \%$, giving an overall smaller deviation from the mean than this NC test, which suggests the outdoor environmental conditions may contribute to such difference. However, there are two major differences between these two studies; chamber size and ambient conditions, both of which can lead to such a difference in results. To identify which of these two factors caused this discrepancy, the impact of the chamber size on the measurement is evaluated in section 6 .

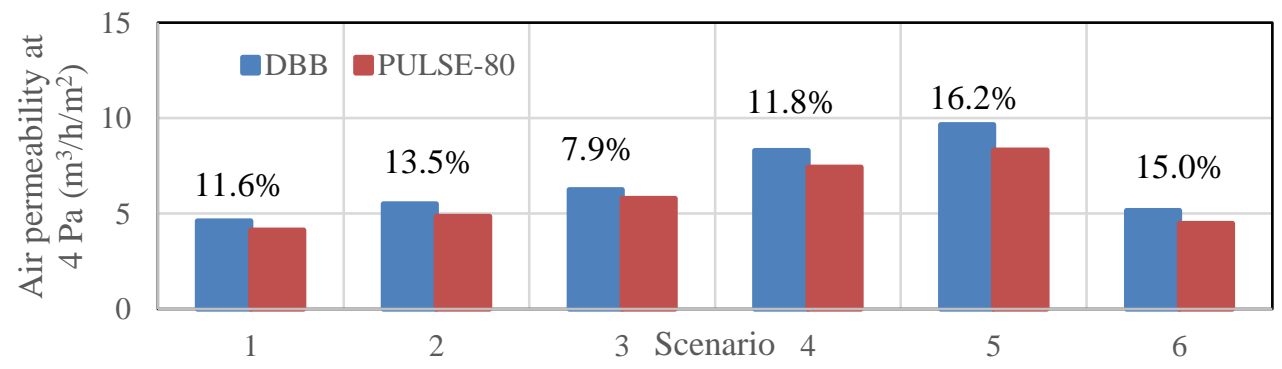

Figure 16 Trend of $\mathrm{Q}_{4}$ in the six scenarios given by DBB in pressurisation mode and PULSE-80

To further investigate this difference, more tests were added to scenario 6. A pressurisation test using an alternative blower door, a larger Minneapolis Blower Door-model 2 (BD-2), was trialled. The result is listed in Table 6 and it showed a difference of $35.9 \%$ compared to PULSE-80 and 
$18.2 \%$ to $\mathrm{DBB}$ for this case study, which is a non-insignificant difference. The installation of the blower doorframe could contribute to this difference. To investigate the potential impact of this, further PULSE-80 tests were carried out, whilst the separate blower door was in-situ with fan openings sealed, i.e. to obtain the effect of the doorframe in isolation. The same door opening was used for the blower door installation in each case; whilst the other chamber door remained closed. The $Q_{4}$ results in the last two columns in Table 6 given by the PULSE- 80 suggest the envelope leakage was increased by $10.3 \%$ and $14.1 \%$ for the DBB and BD-2 installations respectively, when compared to the PULSE 80 test performed with the external doors fully closed. Considering the repeatability of PULSE-80 in this case study, it is highly likely that the installation of the blower door units contributed to increased leakage in the chamber envelope.

However, a $18.2 \%$ difference between the $Q_{4}$ measured in the pressurisation tests between BD2 and DBB was observed. The $Q_{4}$ measured by PULSE- 80 when the BD- 2 was installed is only $3.4 \%$ greater than that when DBB was installed. which suggests the envelope and installation leakage condition for DBB and BD-2 is very close. Hence, it is more likely the difference in $Q_{4}$ given by DBB and BD-2 was mainly caused by model difference in blower door equipment. The deviation from the mean of the PULSE-80 tests was increased from $\pm 1.2 \%$ to $\pm 8.0 \%$ and $\pm 2.2 \%$ when DBB and BD-2 were installed respectively. There is insufficient data to draw any conclusion, but the Pulse results suggest the installation of blower door has an impact on measured results in this case study. This impact on the PULSE-80 repeatability may have been caused by the blower door fabric flexing when the pulse was fired, which consequently led to slight variation in the reading of chamber pressure.

Table $6 Q_{4}\left(\mathrm{~m}^{3} / \mathrm{h} / \mathrm{m}^{2}\right)$ of the chamber measured by DBB and PULSE- 80 in scenario 6

\begin{tabular}{c|c|c|c|c|c}
\hline Test & PULSE-80 & $\begin{array}{c}\text { DBB } \\
\text { Pressurise }\end{array}$ & BD-2 Pressurise & $\begin{array}{c}\text { PULSE-80 (DBB } \\
\text { installed) }\end{array}$ & $\begin{array}{c}\text { PULSE-80 (with BD-2 } \\
\text { installed) }\end{array}$ \\
\hline 1 & 4.46 & 4.71 & 6.51 & 4.74 & 5.05 \\
\hline 2 & 4.44 & 5.20 & 5.55 & 4.75 & 5.05 \\
\hline 3 & 4.53 & 5.55 & 6.20 & 5.34 & 5.22 \\
\hline Mean & $4.48( \pm 1.2 \%)$ & $5.15( \pm 8.6 \%)$ & $6.09( \pm 8.8 \%)$ & $4.94( \pm 8.0 \%)$ & $5.11( \pm 2.2 \%)$ \\
\hline
\end{tabular}




\section{STEADY WIND TESTS (SW)}

\subsection{SW Test arrangement}

In the SW tests, the enclosure was subject to an imposed external wind delivered by the portable trailer fan shown in Figure 9. Various levels of chamber leakage were achieved for testing by sealing up openings, to provide 3 testing scenarios as shown in Table 7. Scenario 3 was further split into two separate tests, by changing the pointing angle of the portable fan, thereby changing slightly the externally imposed wind direction.

Table 7 Testing scenarios for SW tests

\begin{tabular}{|c|c|c|c|c|}
\hline Scenario & 1 & 2 & $3 a$ & $3 \mathrm{~b}$ \\
\hline $\begin{array}{l}\text { Weather } \\
\text { condition }\end{array}$ & $\begin{array}{c}\text { mph } \\
\text { meteorological } \\
\text { wind speed with } \\
\text { sunny spells }\end{array}$ & $\begin{array}{l}7.5 \text { mph meteorological wind } \\
\text { speed with sunny spells }\end{array}$ & \multicolumn{2}{|c|}{$\begin{array}{l}5 \mathrm{mph} \text { meteorological wind speed } \\
\text { with sunny spells. }\end{array}$} \\
\hline Sealed openings & S-1 & S-1, S-2, S-3, R3-1 & \multicolumn{2}{|c|}{$\mathrm{S}-1, \mathrm{~S}-3, \mathrm{R} 3-1, \mathrm{~F} 1-3, \mathrm{~F} 2$} \\
\hline Vent conditions & $\begin{array}{c}\text { Shower extract vent } \\
\text { was sealed }\end{array}$ & $\begin{array}{l}\text { Shower extract, tumble drier } \\
\text { vent, cooker hood vent, and } \\
\text { static vent were sealed }\end{array}$ & \multicolumn{2}{|c|}{$\begin{array}{l}\text { shower extract, radiator vent, cat } \\
\text { flap, cooker hood vent, and static } \\
\text { vent were sealed }\end{array}$} \\
\hline Wind direction & 1 & 1 & 1 & 2 \\
\hline Baseline & Fan off & Fan off & Fan off & Fan off \\
\hline Wind $1(\mathrm{~m} / \mathrm{s})$ & $2.5-3.5$, up to 4 & 2.5-3.5, up to 4 & 2.5-3.5, up to 4 & 2.5-3.5, up to 4 \\
\hline Wind $2(\mathrm{~m} / \mathrm{s})$ & $4-5$, up to 7 & $4-5$, up to 7 & $\mathrm{n} / \mathrm{a}$ & $\mathrm{n} / \mathrm{a}$ \\
\hline Wind $3(\mathrm{~m} / \mathrm{s})$ & $6.5-7.5$, up to 8.7 & $6.5-7.5$, up to 8.7 & $\mathrm{n} / \mathrm{a}$ & $\mathrm{n} / \mathrm{a}$ \\
\hline Wind $4(\mathrm{~m} / \mathrm{s})$ & $\mathrm{n} / \mathrm{a}$ & $8.5-9.5$, up to 11.7 & $\mathrm{n} / \mathrm{a}$ & $\mathrm{n} / \mathrm{a}$ \\
\hline
\end{tabular}

The setups of the DBB and PULSE-60 unit are shown in Figure 17 and Figure 18, respectively. Figure 18 shows two Pulse units, including a test unit and a development unit. However, the results presented herein are based solely on the tests performed with the former. The DBB tests were conducted by a qualified BSRIA compliance engineer and the testing procedure followed the ATTMA TSL1 [52]. The Pulse tests were conducted under the same experimental conditions as the DBB tests.

Note that the DBB test was only performed for the fan off wind condition as no valid blower door test results could be obtained for conditions where the externally imposed wind was directly 
against the blower door fan. Therefore, only the Pulse tests were performed under various wind conditions. Step tests with three pulses were implemented in all scenarios with a starting tank air pressure between 5.6 and 6.7 bar. Due to the tank being partially charged, the third pulse produced a pressure rise which was too low and therefore inherently suffered from environmental noise; hence this step was omitted in the data analysis.

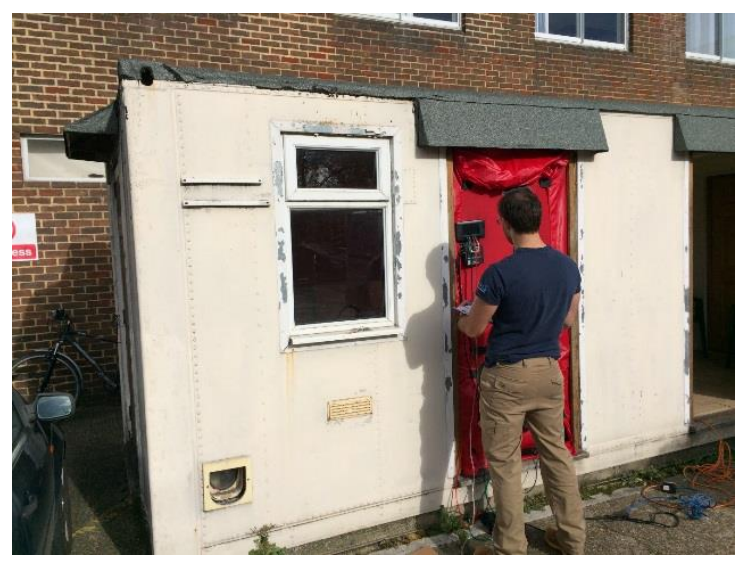

Figure 17 Setup of DBB (SW test)

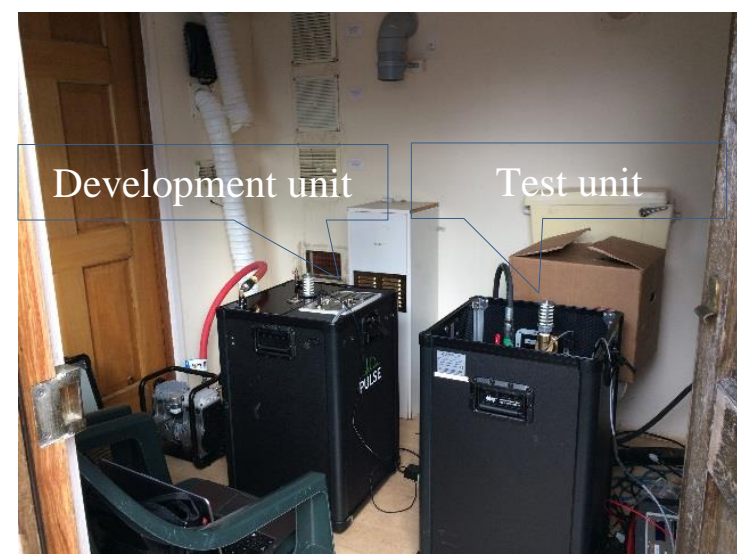

Figure 18 Setup of PULSE-60 (SW test)

As shown in Figure 19, an anemometer was used to measure the wind speed in the centre of the generated airflow and 1 meter away from the corner of the chamber. It was held approximately 1.5 meters above the ground with the measurement duration between 30 and 60 seconds. Due to the fluctuations of wind speed, each level is represented by a range of wind speed with a peak value. For instance, '2.5-3.5, up to 4' means the measured wind speed typically varies between $2.5 \mathrm{~m} / \mathrm{s}$ and $3.5 \mathrm{~m} / \mathrm{s}$, and the recorded maximum wind speed is $4 \mathrm{~m} / \mathrm{s}$. Table 7 lists three testing scenarios achieved by sealing up different openings and using two wind directions. 

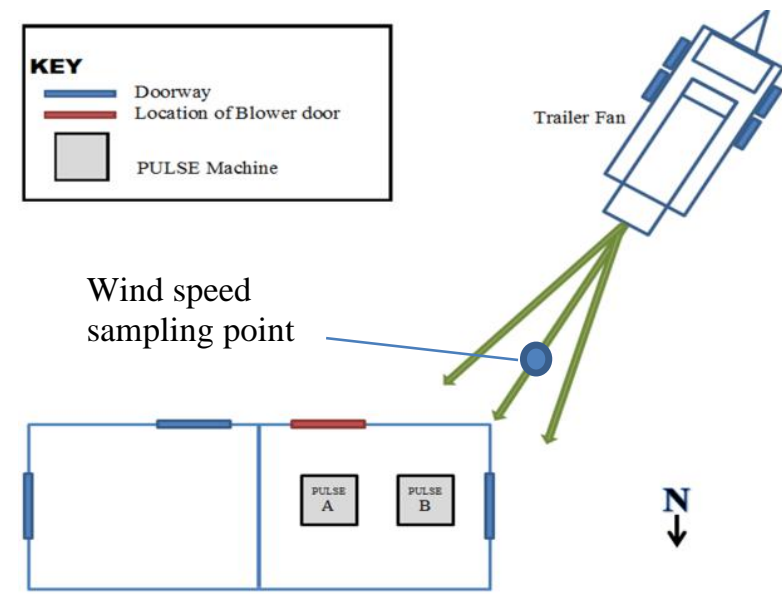

Wind direction 1 (used in scenario 1,2 and 3)

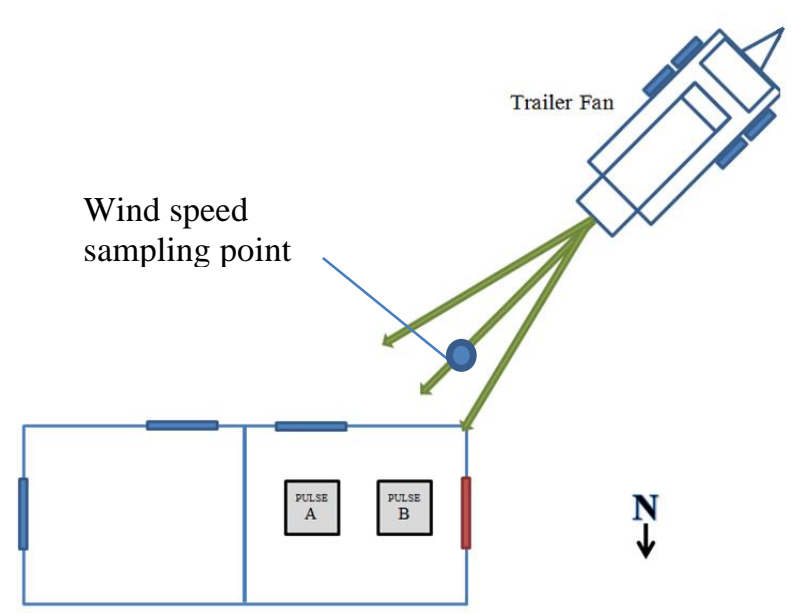

Wind direction 2 (Only used in scenario 3)

Figure 19 Setup of the portable trailer fan in relation to the test chamber

\section{2. SW Test results}

Due to various factors such as small chamber size and limited scenario of wind introduction, this experimental investigation only presents a pilot study on how wind may affect the airtightness measurement of real dwellings using the Pulse technique.

The tank pressures and chamber pressures measured in three repeated pulse tests in three leakage scenarios under the fan-off condition are plotted in Figure 20. The dotted-line and solid line represent the tank air pressure and wind-adjusted chamber pressure respectively; each colour represents a testing scenario. A good repeatability is shown in the pressure pulses with small difference in the magnitude, which was due to the slight difference in starting tank air pressure. The obtained leakage-pressure curves in three scenarios are plotted in Figure 21. In each scenario, the leakage-pressure curves lie closely with each other. Quantitative results are listed in Table 8. 


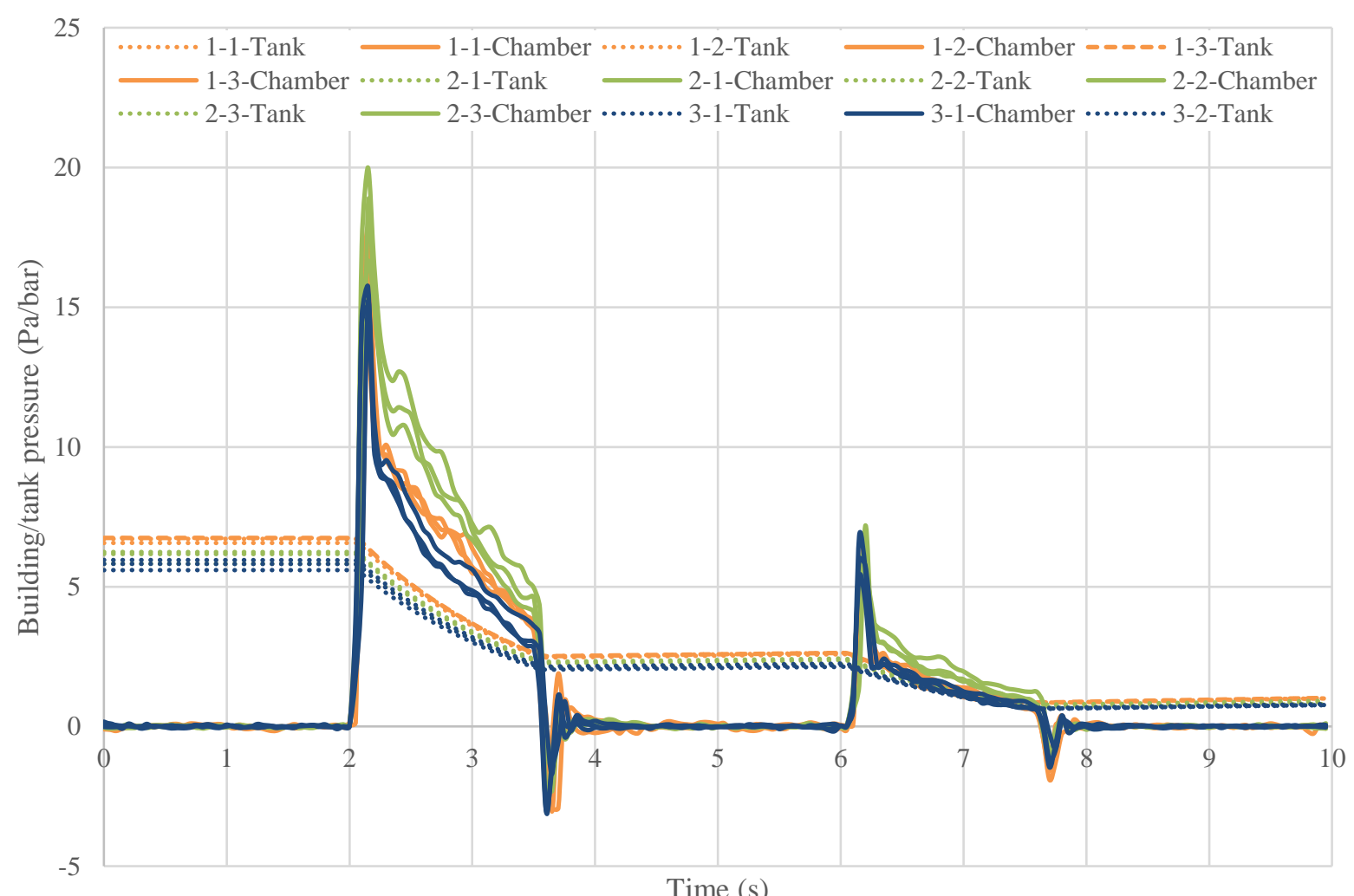

Figure 20 Building and tank pressures measured in three repeated tests of three scenarios (annotation explained: scenario ID-test ID-pressure target; for instance, 1-2-Tank indicates the tank pressure reading in the second test of scenario 1)

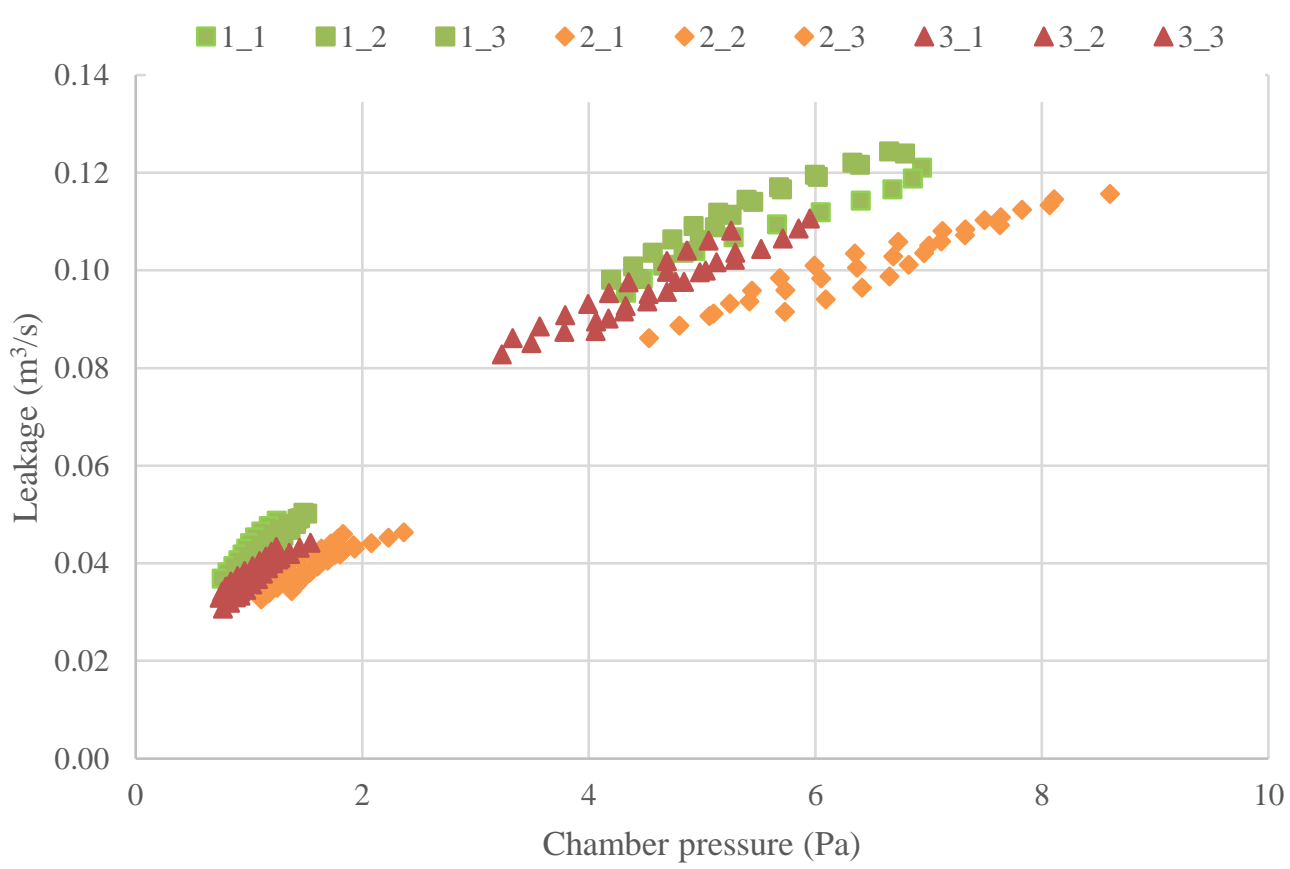

Figure 21 Leakage-pressure curves obtained in three repeated tests in three scenarios (annotation explained: scenario ID_test ID; e.g. 1_2 indicates the second test in scenario 1) 
When the portable fan was off, the air permeability at $4 \mathrm{~Pa}$ of three repeated tests using both PULSE-60 and DBB in each scenario is summarised in Table 8.

Table $8 Q_{4}\left(\mathrm{~m}^{3} / \mathrm{h} / \mathrm{m}^{2}\right)$ measured by DBB and PULSE-60 for fan off condition

\begin{tabular}{|c|c|c|c|}
\hline \multirow[t]{2}{*}{ Equipment } & DBB & PULSE-60 & \multirow{2}{*}{$\begin{array}{c}\text { Mean \% difference between } \\
\text { DBB and PULSE } 60\end{array}$} \\
\hline & $Q_{4}\left(\mathrm{~m}^{3} / \mathrm{h} / \mathrm{m}^{2}\right)$ & $Q_{4}\left(\mathrm{~m}^{3} / \mathrm{h} / \mathrm{m}^{2}\right)$ & \\
\hline \multirow[t]{3}{*}{ Scenario 1: } & 9.87 & 9.89 & \multirow{3}{*}{$-1.69 \%$} \\
\hline & 10.07 & 10.03 & \\
\hline & 9.75 & 10.28 & \\
\hline Mean & $9.90( \pm 1.75 \%)$ & $10.07( \pm 2.10 \%)$ & \\
\hline \multirow[t]{3}{*}{ Scenario 2: } & 8.18 & 7.68 & \multirow{3}{*}{$-1.62 \%$} \\
\hline & 7.70 & 8.09 & \\
\hline & 7.85 & 8.34 & \\
\hline .Mean & $7.91( \pm 3.45 \%)$ & $8.04( \pm 4.41 \%)$ & \\
\hline \multirow[t]{3}{*}{ Scenario 3: } & 9.00 & 9.53 & \multirow{3}{*}{$-10.84 \%$} \\
\hline & 8.95 & 9.48 & \\
\hline & 7.98 & 10.05 & \\
\hline Mean & $8.64( \pm 7.68 \%)$ & $9.69( \pm 3.79 \%)$ & \\
\hline
\end{tabular}

In scenario 1 and 2, a good repeatability has been obtained by both testing methods, and the $Q_{4}$ measured by DBB is smaller than that measured by PULSE-60 by $1.69 \%$ and $1.62 \%$, respectively; however, such differences fall within the measurement uncertainty of both methods $[38,16]$, suggesting a good agreement between the two was achieved. While in scenario 3, the discrepancy increases up to $10.84 \%$. Therefore, similar with results in the NC tests, the range of deviation in the $Q_{4}$ given by both testing methods is also slightly larger than that obtained in the sheltered environment study, but still lies in close vicinity of the measurement uncertainty of blower door [16]. Therefore, this suggests a good agreement on $Q_{4}$ between the two testing methods is achievable in outdoor natural conditions.

Figure 22 shows PULSE-60 readings taken in four different wind conditions, baseline (b1), wind level 1 (w1), wind level 2 (w2) and wind level 3 (w3). For a clearer illustration, only one representative Pulse test is taken from each scenario. The starting tank air pressure in each wind condition was 6.71 bar (bl), 6.81 bar (w1), 6.79 bar (w2) and 6.75 bar (w3) respectively. Therefore, the pulse magnitude of each test is not expected to be identical when the subjected 
wind condition is the same. Nevertheless, the wind had an impact on the reading of chamber pressure but not on the tank pressure due to the tank being isolated at a much higher pressure. Overall, the readings of chamber pressure for each of the tests follow the same trend but with difference in the pulse magnitude and fluctuations. The sinusoidal type of fluctuations are present in the chamber pressure when steady wind is imposed. The higher the wind level is, the greater fluctuation amplitude in the readings of chamber pressure, and seemingly the greater the magnitude of the pulse. This type of fluctuation was likely caused by the way that the wind was generated by the trailer fan, which had six-blade impeller located near the inlet of the duct. The rotation of the fan blades drove the air at the inlet to move towards the outlet to provide artificial wind to the chamber and therefore the fan-generated wind was not $100 \%$ steady but fluctuated in a range.

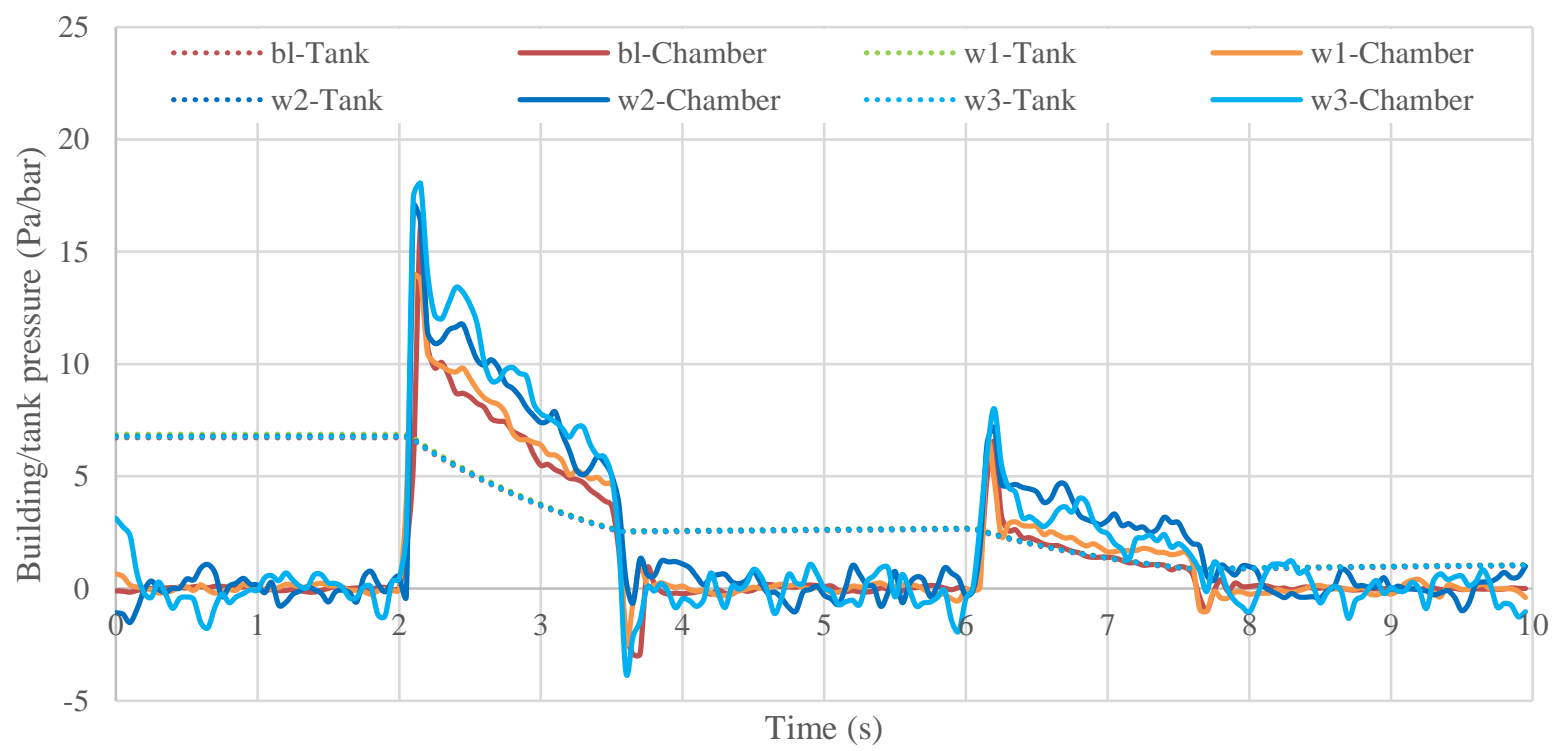

Figure 22 Tank and chamber pressure readings under various wind conditions in scenario 1

Figure 23 shows the leakage-pressure curves obtained in a test under each wind condition when the chamber was tested in scenario 1 where just the shower vent was sealed. Power law trend line has been fitted to the plots with R squared value displayed. In baseline and wind 1 conditions, the leakage-pressure curves lie closely to each other suggesting the wind level 1 had negligible 
impact on the measurement. When the wind level increases, the curves gradually shift away to the right, which implies the chamber envelope becomes more airtight. This trend was also observed in other tests. Results in scenario 2 are similar with scenario 1 and therefore are not plotted in a graph herein. There is an exception that a rather close agreement between baseline and wind level 2 was obtained.

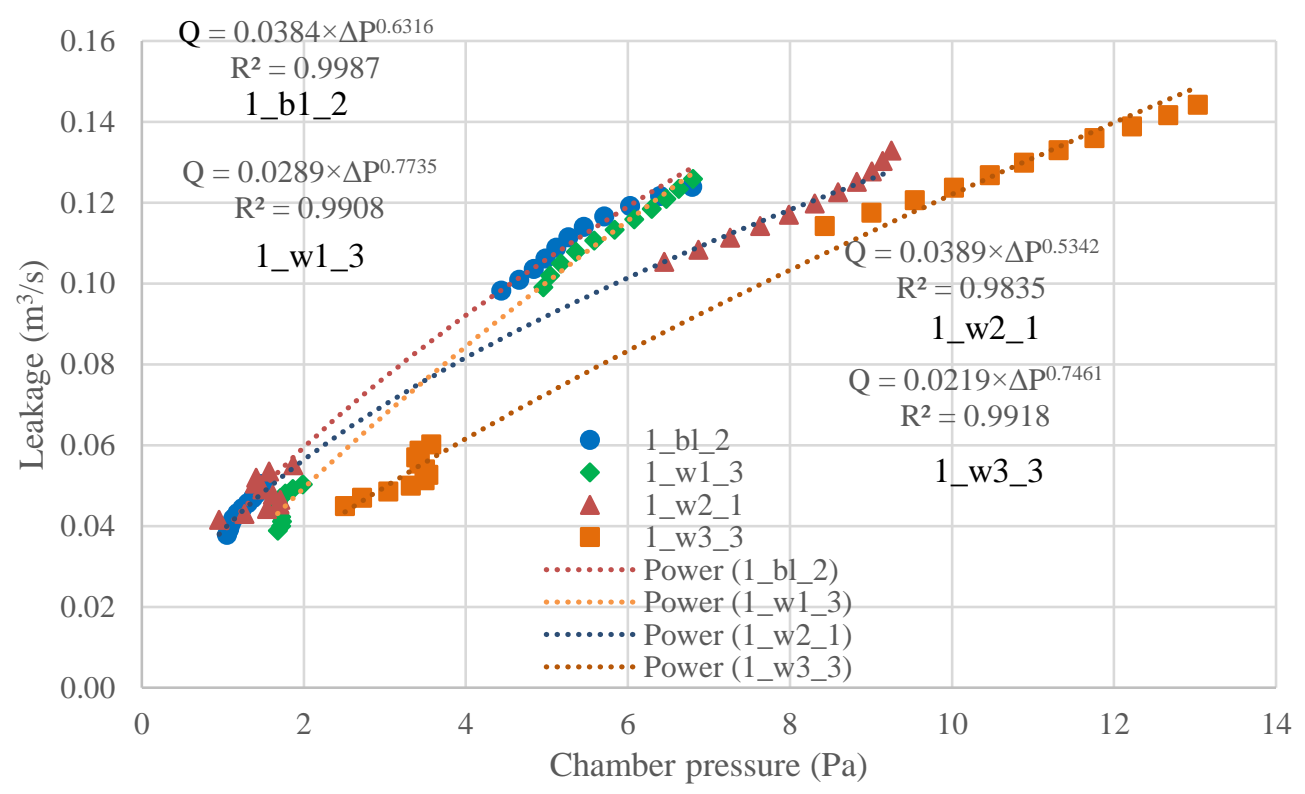

Figure 23 Pressure-leakage curve measured in each wind condition in scenario 1 (bl, w1, w2 and w3 stand for the wind conditions of baseline, wind 1, wind 2 and wind 3; for instance, 1_bl_2 indicates the second test in scenario 1 when the wind condition was baseline)

The measurement of $Q_{4}$ under various wind conditions in three different scenarios is summarised in Table 9. Baseline is the testing scenario where the fan is off. Various wind speeds were achieved, as detailed in Table 7 . In both scenario 1 and 2, a good test repeatability, within $\pm 2.7 \%$ and $\pm 2.1 \%$, respectively, was achieved at wind speed level 1 . The tests at wind speed level 1 under both scenario 1 and 2 also showed good agreement with that done at 'baseline' condition, differing by $-1.9 \%$ and $2.14 \%$ respectively. It suggests the wind speed level 1 did not have significant impact on the Pulse test in the setup given by scenario 1 and 2 and an accurate measurement of $Q_{4}$ at the wind speed level 2 was sometimes achievable. 
Table 9 Impact of various wind conditions on the measurement of $Q_{4}\left(\mathrm{~m}^{3} / \mathrm{h} / \mathrm{m}^{2}\right)$ in three different scenarios

\begin{tabular}{|c|c|c|c|c|c|}
\hline \multicolumn{6}{|c|}{ Scenario 1} \\
\hline Test & Baseline & Wind 1 & Wind 2 & Wind 3 & \\
\hline 1 & 9.89 & 9.86 & 8.42 & 8.13 & \\
\hline 2 & 10.03 & 9.93 & 9.54 & 7.30 & \\
\hline 3 & 10.28 & 9.50 & 7.02 & 8.21 & \\
\hline 4 & 9.61 & $\mathrm{n} / \mathrm{a}$ & $\mathrm{n} / \mathrm{a}$ & $\mathrm{n} / \mathrm{a}$ & \\
\hline Mean & $9.95( \pm 3.4 \%)$ & $9.76( \pm 2.7 \%)$ & $8.33( \pm 15.7 \%)$ & $7.88( \pm 7.3 \%)$ & \\
\hline \multicolumn{6}{|c|}{ Scenario 2} \\
\hline Test & Baseline & Wind 1 & Wind 2 & Wind 3 & Wind 4 \\
\hline 1 & 7.68 & 8.08 & 7.67 & 5.06 & 7.00 \\
\hline 2 & 8.09 & 8.42 & 7.98 & 7.67 & 7.92 \\
\hline 3 & 8.34 & 8.12 & 8.00 & 7.07 & 5.82 \\
\hline 4 & $\mathrm{n} / \mathrm{a}$ & $\mathrm{n} / \mathrm{a}$ & 7.62 & 4.64 & $\mathrm{n} / \mathrm{a}$ \\
\hline Mean & $8.04( \pm 4.4 \%)$ & $8.21( \pm 2.1 \%)$ & $7.82( \pm 2.5 \%)$ & $6.11( \pm 25.6 \%)$ & $6.91( \pm 15.8 \%)$ \\
\hline \multicolumn{6}{|c|}{ Scenario 3 (Baseline and Wind 1 only) } \\
\hline Test & Baseline & Direction 1 & Direction 2 & \multirow{6}{*}{\multicolumn{2}{|c|}{$\mathrm{n} / \mathrm{a}$}} \\
\hline 1 & 9.59 & 8.94 & 8.54 & & \\
\hline 2 & 9.36 & 9.82 & 10.08 & & \\
\hline 3 & 10.10 & 7.39 & 7.27 & & \\
\hline 4 & $\mathrm{n} / \mathrm{a}$ & $\mathrm{n} / \mathrm{a}$ & $\mathrm{n} / \mathrm{a}$ & & \\
\hline Mean & $9.69( \pm 4.3 \%)$ & $8.72( \pm 15.2 \%)$ & $8.63( \pm 16.8 \%)$ & & \\
\hline
\end{tabular}

It can be observed that $Q_{4}$ was decreased across all scenarios by increased wind speed and also results became less repeatable, with ranges from the mean value of an individual test of $\pm 7.3 \%$ (scenario 1, wind 3) to $\pm 25.6 \%$ (scenario 2, wind 3). The decrease in $Q_{4}$ against baseline values was in the range of $2.7 \%-24.0 \%$.

In scenario 3, initial investigations were carried out at wind level 1 to study the impact of the wind direction to the test accuracy and repeatability. Three repeated tests were performed in two aforementioned wind directions; one pointing towards the chamber corner and the other towards the front side of the chamber (Figure 19). The tests done in both wind directions were less repeatable than the baseline with a variation from the mean of $\pm 15.2 \%$ and $\pm 16.8 \%$. These deviations are much greater than that seen in the first two scenarios, which indicates the wind impact on the Pulse test might be affected by the leakage distribution. It can also be observed that the mean results of wind directions 1 and 2 both reported smaller values than the baseline test; providing a relative difference of $10.0 \%$ and $10.9 \%$ respectively. Hence it appears, with the 
relative closeness of the two mean results that the impact of wind direction on the test repeatability and accuracy in the case study is seemingly insignificant. By comparison, increasing wind level in other scenarios from 1 to 2,3 and 4 (i.e. $4.5 \mathrm{~m} / \mathrm{s}-9.0 \mathrm{~m} / \mathrm{s}$ ) shows a greater impact on the repeatability and accuracy of the tests. Although measured at 1.5 meters above the ground level rather than chamber height (2.0 meters), the wind level 1 when converted to that at the chamber height approaches the wind speed $(6.0 \mathrm{~m} / \mathrm{s})$ reported in [32]. However, these findings need further investigation due to insufficient measurements.

\section{IMPACT OF CHAMBER SIZE ON THE PULSE TEST}

The impact of chamber size on the measurement of air leakage needs to be evaluated in order to assess the error that might be introduced to the final calculation by utilising this chamber. For the Pulse test, the building air leakage rate can be calculated by Eq.(4), which mathematically describes the relationship between the real time leakage rate $q\{t\}$ and the chamber volume $V$.

$$
q\{t\}=Q_{p}\{t\}-\frac{V}{\gamma P_{i}} \frac{d P_{i}}{d t}
$$

Where, $P_{i}$ is internal pressure of the chamber, $Q_{p}\{t\}$ is the transient volumetric flow rate of air pulse released from the tank and $q\{t\}$ is the volumetric flow rate of air leakage through building envelope, respectively. Hence, its accuracy can be affected by the measurement of chamber dimensions and presence of tester and pulse unit during testing. To analyse the error in chamber air leakage rate (denoted as $\delta q_{V}$ ) caused by the error in the measurement of the chamber volume $(\delta V)$, Eq.(5) can be derived by using Eq.(4) to provide the quantified impact. 


$$
\delta q_{V}=\frac{\frac{\Delta V}{\gamma P_{i}} \frac{d P_{i}}{d t}}{Q_{p}\{t\}-\frac{V}{\gamma P_{i}} \frac{d P_{i}}{d t}}
$$

Figure 24 shows the impact of the error in the measurement of chamber volume on the final result of $Q_{4}$ given in the Pulse measurement to spaces with three different volumes $\left(13 \mathrm{~m}^{3}, 130\right.$ $\left.\mathrm{m}^{3}, 260 \mathrm{~m}^{3}\right)$. For the test chamber $\left(13 \mathrm{~m}^{3}\right)$ used in this study, an impact of less than $1 \%$ to $Q_{4}$ is observed. This is due to the fact the change in the building envelope airflow associated with the compressibility of air (the second term on the right side of Eq.(4)) represents a small percentage of the overall volumetric flow rate of the released air from the tank and that the chamber size is much smaller than a typical dwelling. However, this does not suggest that the compressibility of the air has negligible impact on the calculation of building air leakage rate and therefore this term should be ignored in Eq.(4), because it can be significantly enhanced when the size of the test space increases, as illustrated by Figure 24. An increased volume of the test space leads to greater impact of the error in the measurement of building volume on the final result. For the measurement uncertainty of the building volume, it typically ranges from $3 \%$ to $10 \%$ [53]. Due to the small volume of the test chamber used within this study, the presence of the pulse unit and the testers can stand for a relatively larger proportion of the chamber volume, which represents up to $0.3 \mathrm{~m}^{3}$, i.e. $2.3 \%$. However, the impact these combined errors have on $Q_{4}$ is still less than $0.1 \%$. Therefore, the size of the test chamber used in this study has negligible impact on the measurement of chamber leakage and the use of the chamber can be justified for the intended purpose of this study. 


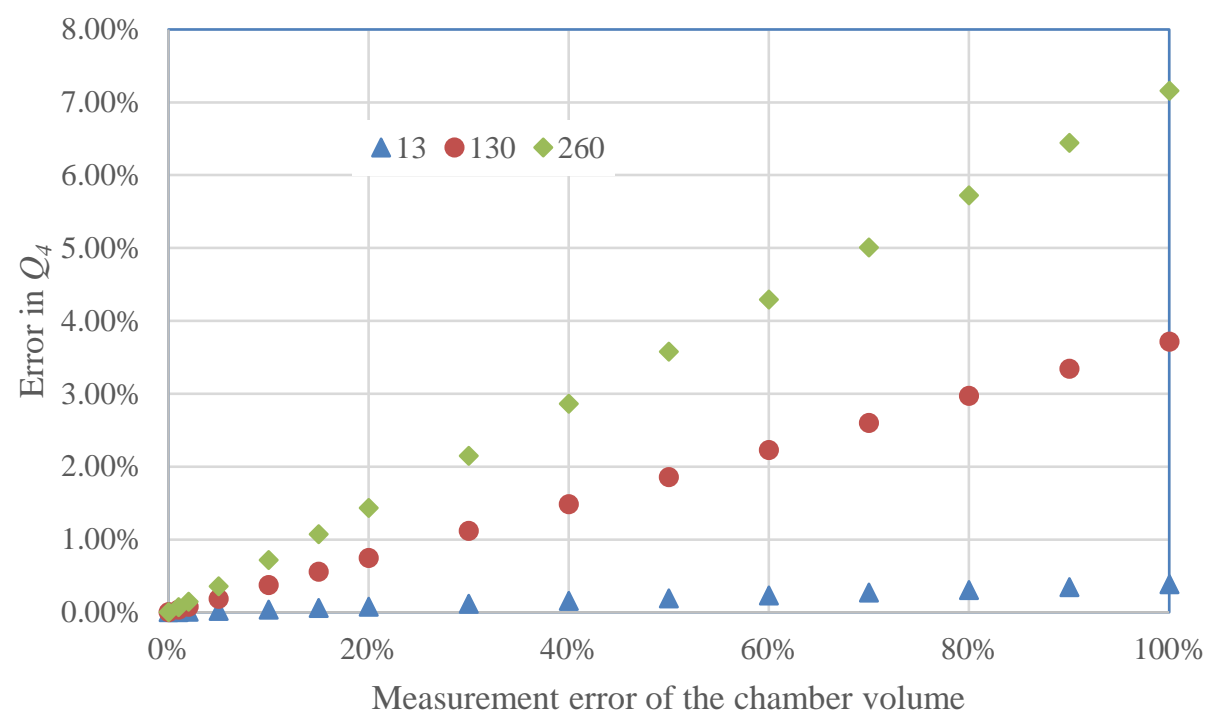

Figure 24 Impact of the measurement error of the chamber volume on $Q_{4}$

Apart from the size of test space, other sources of overall measurement error also include the readings of air pressure and temperature in the building and air tank, as well as the measurement of tank volume. The measurement uncertainty caused by these factors has been introduced by Zheng et al in [26] and therefore is not discussed herein.

\section{OBSERVATION AND DISCUSSION}

The previous study [26] performed in a sheltered condition showed the blower door and Pulse methods were able to directly measure the leakage at low pressure due to the reduced impact of environment conditions and good agreement (0-5.3\%) between the two under various leakage scenarios were achieved. Considering the blower door method is a scientific sound and reliable means for measuring building leakage, this finding suggests the Pulse technique as an unsteady approach that is designed to take measurements directly at low pressure is a feasible and reliable testing method for measuring building leakage. 
Although the outdoor environment condition is a likely contributor to the increased difference between the airtightness measurements given by both testing methods in comparison to the sheltered condition study, a good agreement between the two methods is still achievable in natural conditions. Therefore, when adverse wind condition is absent, small blower door method model is able to offer reliable measurement directly at low pressure. However, with assistance of the Pulse technique, it was found that the installation of blower door unit in the door way can lead to varied leakage of the test enclosure. Slight difference in measurements was also observed when different blower door models were used, which indicates different blower door model is designed to provide the optimal accuracy over a different flow range. The Pulse technique, able to account for background pressure noises caused by the wind and buoyancy effects by delivering short time operations and using algorithms for adjustment, provides accurate and reliable measurements at low pressure only under certain ground level wind speed $(3.5 \mathrm{~m} / \mathrm{s})$ in this case study.

Compared to the chamber used in the sheltered environment [26], the test chamber used in this study has an internal volume of $13 \mathrm{~m}^{3}$, about 20 times smaller than a typical UK dwelling. However, three background vents were installed to the chamber enclosure to provide a leakage level that is present in a typical UK dwelling. This arrangement enabled a large amount of airflow to occur to achieve the required pressure range for testing. For the pulse units used in the tests, the pressure sensing section was exposed to the air and hence prone to be affected by surrounding air movement. When the compressed air was released into the test chamber in this study, air movement was produced during the equalisation process as the airflow was reflected by interior surfaces in the confined chamber space. Hence, fluctuations in the measurement of chamber pressure were seen in some of the tests and the repeatability can be affected slightly. 
In order to determine if the uncertain nature of environmental factors presented in the natural condition contributes to the difficulty of measuring low pressures accurately, it is better to use a test chamber of similar size in both sheltered and unsheltered environments. In this way, any differences due to different volume and envelope area can be eliminated. However, due to availability of an unsheltered test facility (and consideration of the practicality of introducing steady wind manually in the SW tests), a chamber of half the size of a standard 20 feet shipping container was used. This chamber is much smaller than the house-sized chamber used in the sheltered environment [26], and therefore, the NC test in this small chamber should be regarded as a pilot study for outdoor comparison and the conclusion drawn in the NC tests should not necessarily be applied to normal houses. Further experimental investigation needs to be performed to determine if the conclusions drawn in this study stand for real houses.

In the steady wind tests, it was observed due to the function of the fan equipment (as detailed in section 5.2) that the measured wind speed was not fixed at a particular level but fluctuated in a range due to the nature of blade movement. Hence, a stable steady wind could not be obtained in this case study, but represented by a range of wind speeds. Due to the limited space between the chamber and the adjacent objects such as parked vehicles and a building, the portable fan could only be set up in front of the chamber. Hence, only two different wind directions were implemented for testing. Further tests including wind flow from each side of the envelope with different opening distributions should be performed to investigate the impact of the wind direction and distribution of openings on the test results systematically.

\section{CONCLUSION}

The first investigation in this study looked at how Pulse and the blower door methods compared in measuring the chamber envelope airtightness in six different leakage scenarios under the 
natural outdoor condition (NC). It has been found that for NC tests the $Q_{4}\left(\mathrm{~m}^{3} / \mathrm{h} / \mathrm{m}^{2}\right)$ given by both blower door and the Pulse methods followed a close and similar trend, with the DBB measurement being higher than the Pulse measurement by $7.9 \%-16.2 \%$, which is a slightly larger discrepancy than what was found in a sheltered environment study [54]. This difference could be largely attributed to the combination of unsheltered outdoor weather condition and extrapolation, partially attributed to blower door installation and difference in the chamber.

In the second experiment, the repeatability of Pulse under various artificially imposed steady wind (SW) speeds and directions was investigated. In scenario 1 and 2, the envelope arrangement was made different by the sealing of different openings and with no wind applied, good agreement of $Q_{4}$ given by both techniques was observed ( $\left.<2 \%\right)$. However, in scenario 3 with no wind applied, which involved another vent sealing arrangement, the deviation between results increased up to $10.84 \%$, but giving a similar overall deviation range with that obtained in the NC tests. Hence, it is considered that the impact of the outdoor environmental condition is a likely contributor to the increase in deviation between the two methods in measuring $Q_{4}$. However, a good agreement between the two methods was proved to be achievable in natural outdoor condition. At wind level 1 (wind speed up to $3.5 \mathrm{~m} / \mathrm{s}$ ) for scenarios 1 and 2, a good repeatability $(< \pm 3 \%)$ was obtained in the pulse test and the $Q_{4}$ reported by PULSE- 60 differed from that in the fan-off tests by $<2.2 \%$. However, this close agreement did not follow in scenario 3, where for wind direction 1 and 2, the $Q_{4}$ decreased from baseline by $10 \%$ and $10.9 \%$ respectively, suggesting the opening distribution might change the way wind affects the Pulse measurement. When the wind speed was increased to between $4.5 \mathrm{~m} / \mathrm{s}$ and $9 \mathrm{~m} / \mathrm{s}$, (wind levels 2 , 3 and 4) the Pulse test became less repeatable, with uncertainty from the mean value increasing up to $\pm 25.6 \%$ and the $Q_{4}$ decreasing by $2.7 \%-24 \%$. This steady wind study provides insight of how wind affects the Pulse measurement based on a small outdoor chamber. These tests represent the observations seen on a limited number of tests for this case study and further experimental 
investigations are now required in the field of actual dwellings to determine the validity of the findings in this study. However, considering the difficulty of introducing steady wind to actual dwellings, testing a scaled-down model house in a wind tunnel seems to be a more practical approach to investigate the impact of steady wind on the measurement of building airtightness.

\section{ACKNOWLEDGEMENT}

The authors gratefully acknowledge funding received from: the European Union's Horizon 2020 research and innovation programme under grant agreement No 637221. ['Built2Spec': http://www.built2spec-project.eu/].

\section{REFERENCES}

[1] United Nations

Paris Agreement 2015

Available from:

https://unfccc.int/files/essential_background/convention/application/pdf/english_paris_agreeme $\underline{\text { nt.pdf }}$

[2] D. Etheridge

A perspective on fifty years of natural ventilation research

Building and Environment (2015), 91, pp.51-60.

[3] AIC

Air infiltration instrumentation and measuring techniques

$1^{\text {st }}$ AIC Conference, Windsor, Berkshire, UK, 6-8 October, 1980

[4] J. Jokisalo, J. Krunitski, M. Korpi, T. Kalamees, J. Vinaha

Building Leakage, infiltration, and energy performance analyses for Finnish detached houses

Building and Environment 44 (2009) 377-387.

[5] G Raman, K Chelliah, M. Prakash, R.T.Muehleisen

Detection and quantification of building air infiltration using remote acoustic methods

Inter. Noise 2014, Melbourne, Australia. 16-19 November, 2014.

[6] National Institute of Standards and Technology (1996)

NIST estimates nationwide energy impact of air leakage in U.S. buildings

Journal of Research of the NIST 101(3): 413.

[7] S.J. Emmerich., A.K. Persily 
Energy impacts of infiltration and ventilation in U.S. office buildings using multizone airflow simulation

IAQ and Energy 98, pp.191-203.

[8] Jokisalo, J. Krunitski, M. Korpi, T. Kalamees, J. Vinaha

Building Leakage, infiltration, and energy performance analyses for Finnish detached houses

Building and Environment 44 (2009) 377-387.

[9] H. Ross

"Air Infiltration," Lecture at Public Meeting

DoE, Division of Building and Community Systems, Architectural and Engineering Systems Branch, 21 September 1978.

[10] Kirkwood RC (1977)

Fuel consumption in industrial buildings

Building Services Engineer 45(3): 23-31

11] Nevrala DJ and Etheridge DW (1977)

Natural ventilation in well-insulated houses

In: Proceedings of International Centre for Heat and Mass Transfer, International Seminar, UNESCO, Volume.

[12] Caffey GE (1979)

Residential air infiltration

ASHRAE Transactions 85: 919-926.

[13] UNEP

Buildings and Climate Change, Summary for Decision-Makers

Sustainable Buildings \& Climate Initiative, 2009. Available from:

http://www.unep.org/sbci/pdfs/SBCI-BCCSummary.pdf

[14] L. Lombard, J. Ortiz, C. Pout

A review on buildings energy consumption information

Energy and Buildings 40 (2008) 394-398.

[15] International Energy Agency, 2013

Transition to Sustainable Buildings-Strategies and Opportunities to 2050

Available from:

http://www.iea.org/Textbase/npsum/building2013SUM.pdf

[16] BS EN ISO 9972

Thermal performance of buildings-Determination of air permeability of buildings-Fan pressurisation method

BSI Standards Publication (2015)

[17] M.H. Sherman, R. Chan

Building Airtightness: Research and Practice

Lawrence Berkeley National Laboratory Report (2004), Report No. LBNL-53356.

[18] Henry R. and Patenaude A. 
Measurements of Window Air Leakage at Cold Temperatures and Impact on Annual Energy Performance of a House

ASHRAE Transactions, Vol. 104 (1b), 1998, pp. 1254-1260

[19] Cummings J.B., Withers C.R., Moyer N.A., Fairey P.W., McKendry B.B.

Uncontrolled Air Flow in Non-Residential Buildings

Final Report, FSEC-CR-878-96, Florida Energy Solar Center, 1996

[20] Air-Leakage-Control-in-Multi-Unit-Residential-Buildings, available from:

http://www.airbarrier.org/ycdt/wcm-

docs/docs/CMHC\%20Air\%20Leakage\%20Control\%20in\%20MURBs\%20-\%20Research\%20

Report\%20Final\%20-\%20Compiled.pdf

[21] Cooper EW, Etheridge DW. (2007)

Determining the adventitious leakage of buildings at low pressure. Part 2: pulse technique

Building Serv. Eng. Res. Technol; 28: 81-96.

[22] Cooper E., Zheng X.F., Gillot M., Riffat S., Zu Y.Q.(2014)

A nozzle pulse pressurisation technique for measurement of building leakage at low pressure

35th AIVC Conference "Ventilation and airtightness in transforming the building stock to high performance", Poznan, Poland, 24-25 September 2014.

[23] D. Etheridge

A perspective on fifty years of natural ventilation research

Building and Environment (2015), 91, pp.51-60

[24] M. Sandberg, M. Mattsson, H. Wigo, A. Hayati, L. Claesson, E. Linden, M. A. Khan Viewpoints on wind and air infiltration phenomena at buildings illustrated by field and model studies

Building and Environment (2015), 92, pp.504-517

[25] Hsu Y.S., Zheng X.F., Cooper E.W., Gillott M., Lee S.K., Wood C.J.

Evaluation of indoor pressure distributions in a detached house using the Pulse airtightness measurement technique

in: 40 ${ }^{\text {th }}$ AIVC conference, Ghent, Belgium, 15-16 October 2019.

[26] Zheng X.F., Cooper E., Mazzon J., Wallis, I., Wood, C. J.

Experimental insights into the airtightness measurement of a house-sized chamber in a sheltered environment using blower door and pulse methods

Building and Environment (2019), 162. https://doi.org/10.1016/j.buildenv.2019.106269

[27] M.J. Lee, N. Kim, H.S. Ryou

Air tightness measurement with transient methods using sudden expansion from a compressed chamber

Building and Environment 46 (2011) 1937-1945

[28] Bae, S. et al., 2013

Improvement in the applicability of the air tightness measurement using a sudden expansion of compressed air

Building and Environment, Volume 61, pp. 133-139 
[29] X.F. Zheng, E. Cooper, Y.Q. Zu, M. Gillott, D. Tetlow, S. Riffat, C.J. Wood Experimental Studies of a Pulse Pressurisation Technique for Measuring Building Airtightness

Future Cities and Environment (2019), 5(1): 10, 1-17 DOI: https://doi.org/10.5334/fce.66

[30] M. Sherman, L. Palmiter

Uncertainty in fan pressurisation measurements

Airflow Performance Conference, ASTM International, West Conshohocken, PA, 1995, pp.

266-283, https://doi.org/10.1520/STP14701S

[31] Carrie F.R., Melois A., 2020

Modelling building airtightness pressurisation tests with periodic wind and sharp-edged openings

Energy and Buildings 208 (2020)109642

[32] Carrie F.R., Leprince V, 2016

Uncertainties in building pressurisation tests due to steady wind. Energy and Buildings Vol.116, 15th March 2016, pp 656-665

[33] LEPRINCE, V. \& CARRIé, F. R

On the contribution of steady wind to uncertainties in building pressurisation tests 38th AIVC - 6th TightVent - 4th venticool Conference, 13-14 September 2017 Nottingham, UK.

[34] LEPRINCE, V. \& CARRIé, F. R. 2018

Uncertainties due to steady wind in building pressurisation tests

REHVA Journal, 03, 53-57

[35] KRANIOTIS, D. 2014

Dynamic characteristics of wind-driven air infiltration in buildings The impact of wind gusts under unsteady wind conditions

Norwegian University of Life Sciences.

[36] KRANIOTIS, D., AURLIEN, T. \& THIIS, T. 2014

Investigating instantaneous wind-driven infiltration rates using the $\mathrm{CO} 2$ concentration decay method

International Journal of Ventilation, 13, 111-124

[37] KRANIOTIS, D., THIIS, T. K. \& AURLIEN, T.

Wind direction and leakage distribution in buildings. A CFD transient analysis of their impact on air exchange rates under unsteady wind conditions

6th European-African conference on wind engineering(EACWE 2013), 2013

[38] E.W. Cooper, X.F. Zheng, C.J. Wood, M. Gillott, D. Tetlow, S. Riffat, L.D. Simon

Field trialling of a pulse airtightness tester in a range of $\mathrm{UK}$ homes

Int. J. Ventilation, 18(1) (2019), pp.1-18.

[39] Zheng X.F., Mazzon J., Wallis, I., Wood, C. J.

Experimental study of enclosure airtightness of an outdoor chamber using the pulse technique and blower door method under various leakage and wind conditions 
In: 39th AIVC - 7th TightVent \& 5th venticool Conference, 18-19 September 2018, Antibes Juan-Les-Pins. 352-362

[40] A. Anderson

The history of the blower door

Home Energy Magazine Online November/December 1995,

http://homeenergy.org/show/article/year/1995/id/1171

[41] C. Delmotte, J, Laverge

Interlaboratory test for the determination of repeatability and reproducibility of buildings airtightness measurements

$32^{\text {nd }}$ AIVC Conference Proceedings. Brussels, Belgium: 12-13 October 2011

[42] Prignon, M. \& Van Moeseke, G., 2017

Factors influencing airtightness and airtightness predictive models: a literature review Energy and Buildings, Volume 146, pp. 87-97

[43] Baracu, T. et al., 2017

Consideration of a new extended power law of air infiltration through the building's envelope providing estimations of the leakage area

Energy and Buildings, Volume 149, pp. 400-423

[44] M.H. Sherman, D.T. Grimsrud

Infiltration-pressurization correlation: Simplified physical modelling

ASHRAE Trans. 86, II (1980): PP. 778-807. Lawrence Berkeley Laboratory Report, LBL10163.

[45] Howieson, S., Sharpe, T., Farren, P., 2014

Building tight - ventilating right? How are new air tightness standards affecting indoor air quality in dwellings?

Building Services Engineering Research \& Technology, 35(5), pp. 475-487

[46] Sinott, D., Dyer, M., 2012

Air-tightness Field Data for Dwellings in Ireland

Building and Environment, Volume 51, pp. 269-275

[47] R.J. Lowe, D. Johnston, M. Bell

Airtightness in UK dwellings: a review of some recent measurements

Available from: https://www.aivc.org/sites/default/files/airbase_10669.pdf

[48] M. Gillott, D.L. Loveday, J. White, C.J. Wood, K. Chmutina, K. Vadodaria.

Improving the airtightness in an existing UK dwelling: the challenges, the measures and their effectiveness

Building and Environment (2016), 95, pp. 227 - 239

[49] S. Sharples, S. Closs, N. Chilengwe

Airtightness testing of very large buildings: a case study

Building Serv. Eng. Res. Technol. (2005), 26(2), pp. 167-172

[50] D.W. Etheridge 
Unsteady flow effects due to fluctuating wind pressures in natural ventilation designinstantaneous flow rates

Building Environ (2000); 35, pp.111-133

[51] M. Orme, M. Liddament, A.Wilson

An Analysis and Data Summary of the AIVC's Numerical Database

Technical Note 44 (1994), Air Infiltration and Ventilation Centre

[52] ATTMA Technical standard L1

Measuring air permeability in the envelopes of dwellings

The Air Tightness Testing \& Measurement Association (2016)

[53] BS EN ISO 9972

Thermal performance of buildings-Determination of air permeability of buildings-Fan pressurisation method

BSI Standards Publication (2015)

[54] X.F. Zheng, E. Cooper, J. Mazzon, I. Wallis, C. J. Wood., 2017

A comparison study of the blower door and novel pulse technique on measuring enclosure airtightness in a controlled environment

In: 38th AIVC conference, Nottingham, United Kingdom, 13-14 September 2017. 